\title{
More than one story: A bioecological model of elementary educators' perceptions and representations of diversity
}

\author{
Angela Curfman \\ West Liberty University, aicard@mix.wvu.edu
}

Follow this and additional works at: https://researchrepository.wvu.edu/etd

Part of the Curriculum and Instruction Commons, Elementary Education Commons, Language and Literacy Education Commons, and the Teacher Education and Professional Development Commons

\section{Recommended Citation}

Curfman, Angela, "More than one story: A bioecological model of elementary educators' perceptions and representations of diversity" (2021). Graduate Theses, Dissertations, and Problem Reports. 10320. https://researchrepository.wvu.edu/etd/10320

This Dissertation is protected by copyright and/or related rights. It has been brought to you by the The Research Repository @ WVU with permission from the rights-holder(s). You are free to use this Dissertation in any way that is permitted by the copyright and related rights legislation that applies to your use. For other uses you must obtain permission from the rights-holder(s) directly, unless additional rights are indicated by a Creative Commons license in the record and/ or on the work itself. This Dissertation has been accepted for inclusion in WVU Graduate Theses, Dissertations, and Problem Reports collection by an authorized administrator of The Research Repository @ WVU. For more information, please contact researchrepository@mail.wvu.edu. 
More than one story: A bioecological model of elementary educators' perceptions and representations of diversity

\author{
Angela Curfman \\ Dissertation submitted \\ to the College of Education and Human Services \\ at West Virginia University \\ in partial fulfillment of the requirements for the degree of \\ Doctor of Education in \\ Curriculum and Instruction

\begin{abstract}
Aimee Morewood, PhD., Chair
Allison Swan-Dagen, Ph.D.

Sam Stack, Ph.D.

Maria Genest, Ed.D.

Department of Curriculum and Instruction/Literacy Studies/Social \& Cultural Foundations
\end{abstract}

\title{
Morgantown, West Virginia \\ 2021
}

Key Words: children's literature, diversity, elementary education, bioecological model Copyright 2021 Angela Curfman 


\begin{abstract}
More than one story: A bioecological model of elementary educators' perceptions and representations of diversity
\end{abstract}

Angela Curfman

Classroom teachers have long employed children's literature in the classroom. Exposure to children's literature offers a plethora of gains and benefits. Through the usage of children's literature, critical thinking skills are fostered and factual information is obtained (Hancock, 2000). Varied cultures, linguistic backgrounds, families with diverse socio-economical, and academic backgrounds constitute our public school classrooms. Children's literature provides readers an opportunity for self-affirmation; therefore, they often seek a mirror in books, (Bishop, 1990). The thoughtful selection of children's literature in the classroom is essential. Through the lens of Bishop's (1993) metaphorical notion of books as mirrors, windows, and sliding glass doors, and Bronfenbrenner's (1994) bioecological model, this research sought to determine how teachers define diversity and represent diversity in children's literature. To achieve this, a descriptive case study approach was enacted. Both in conceptualization and representation in children's literature, the goal of this study was to examine how in-service teachers perceive diversity. 


\section{Dedication and Acknowledgement}

When I was an undergraduate, a faculty member once remarked, "When you are working on your doctorate, never make any major life decisions." Words from the wise may sometimes be heard; however, not implemented. This dissertation is more than a body of research; it is a testimony and narrative of perseverance.

Decades ago, (or so it may slightly exaggerated seem), I applied to the doctoral program at West Virginia University. Within my nuclear family, I wear the badge of a first-generation college graduate. While a master's graduate program was uncharted waters, a doctoral program was analogous to a planetary exploration on the far side of the moon. I applied with a deep breath and depth of uncertainty. With determination in hand, I walked into the final application step: the interview. And this is where my first two characters that must receive the deepest gratitude enter this act: my mother, Mae, and my advisor, Dr. Aimee Morewood. While my mom sat in the car waiting for my return and being my ever-constant supportive pillar in my life, little did Dr. Morewood know what the future would bring to her/us. As she was preparing to deliver her second child, our interests aligned and the advisory match was made, (as well as the delivery of her daughter soon after!). Thus, the adventure began!

Like most well-written voyages, appreciation is best served with high and low tides, and maybe a tsunami or two. In this doctoral journey, the waves called life crashed a time or two, (or twenty). With each storm surge, inner purpose escalated. Toddlers, a divorce, a minor hospital stay-cation called sepsis, a new job, and selling a home crashed aboard; however, this ship did not sink.

This ship, aka the researcher/student/single mom/daughter/partner/professor, did not let life submerge her, nor knock her off track for long. Perseverance and a supportive team that I am 
forever indebted to must receive acknowledgement. Words cannot be written or expressed that appropriately reveal my gratitude; however, the next few paragraphs include my verses of acknowledgment and gratitude to those that have been instrumental in keeping me/this ship afloat.

To my committee members: Drs. Genest, Swan-Dagen, Stack, your support and advice has been incredible. Your thoughts, suggestions, revisions, and interactions have greatly influenced and impacted my professional development and dissertation journey. I thank you for sharing your knowledge and experience. I thank you for your contributions and spending your valuable time with me. Thank you, thank you, thank you.

To my advisor, Dr. Morewood, words cannot even describe how deeply grateful I am to you. The amount of time that you have spent with me, never giving up on me, and your unparalleled support is nothing short of incredible. I thank you for your acceptance that the appropriate pronoun for you and me is we. It truly is 'we.' We have done this, there is nothing about 'I' in this journey. Thank you, thank you, thank you.

To my partner, Craig, I thank you for believing in me. I thank you for reminding me that this accomplishment is truly an accomplishment for my family. I must admit, your mantra "work smarter, not harder," is one that I am still attempting to master. Your words frequently echo in my head as I would spend two hours debating on the best word to use in a sentence or when I thought I needed to add just one more table because it was needed. Thank you, thank you, thank you.

To my parents, Mae and Dave, once more, words cannot begin to describe your unwavering support and dedication. From keeping me awake as I would drive two hours home from Dr. Stack's class that would end at 10:00pm to just reminding me "I can do this." To those 
nights when I wondered if I could face the rising sun, when Dave would quietly tell me, "This too shall pass," to the countless tears that my mom would never hesitate to collect. Thank you, thank you, thank you.

To Lane and Emmerson, my children, thank you for allowing me to be their momma. I love you both to the moon and beyond. I hope I make you proud, as you make me proud every day. Thank you, thank you, thank you.

A dissertation is so much more than research. A dissertation is powerful evidence of what one can accomplish when they are surrounded by a supportive team. A dissertation is an emotional narrative that provides insight into one's character. My deepest gratitude and acknowledgment are extended to those that have contributed so much time and effort into me, into this journey. Thank you, thank you, thank you. 


\section{Contents}

Chapter I

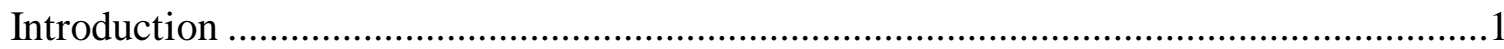

Chapter II

Literature Review............................................................. 11

Chapter III

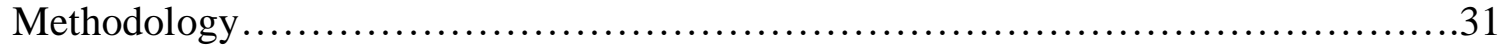

Chapter IV

Findings..............................................................43

Chapter V

Conclusion and Discussion...................................................64

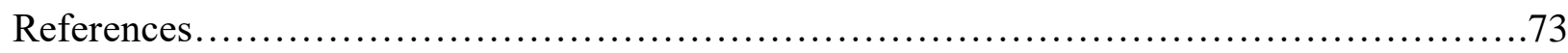

Appendix A

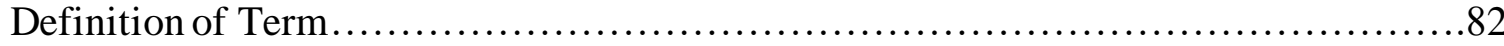

Appendix B

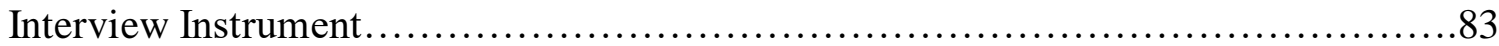

Appendix C

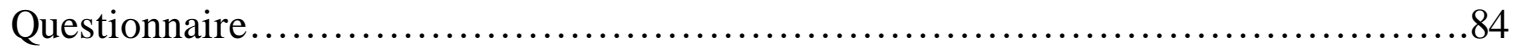

Appendix D

Dual Theoretical Framework Alignment to Instrument Design Crosswalk

Appendix E

The ILA Standards for the Preparation of Literacy Professionals 2017 Standard 4

Diversity and Equity

Appendix F

Bronfenbrenner's Bioecological Systems Theory Five Connected Configuration .88 


\section{More than one story: A bioecological model of elementary educators' perceptions and representations of diversity}

\section{Chapter I: Introduction}

Comparable to windows, children's literature has the capacity to offer readers views of the world that may be imaginative or authentic(Bishop, 1990).

Children's literature has the potential to prompt reflection in self and self-affirmation; however, when children cannot find themselves in that reflection, they can feel devalued in society (Bishop, 1990). In the classroom, children's literature fulfills multiple cognitive and affective learning goals and objectives, including promotion of literacy success and personal motivation. More than ever before, today's classrooms consist of diverse learners with a broad range of varied backgrounds and exceptionalities, race, gender, and ability, (Leah \& Foley, 2018; Mihic et al., 2017). The inclusion of children's literature to support diversity in the classroom has the potential to create an inclusive classroom. It is with a critical lens that educators must view their usage of children's literature as a potential transformative and reflective experience for their students.

In today's classroom, the expectations placed on the value and role of children's literature have shifted. Educators use children's literature for various reasons, including achievement of learning standards and educational goals. In the last several decades, the emphasis on and the role that children's literature plays in the classroom has varied due to multiple factors, including legislation trends. Since the early 2000's, legislation trends have ranged from the No Child Left Behind (NCLB) Act (with an increased demand on rigorous instruction in an inclusive environment) to the Common Core Standards (with a lens placed on increased text complexity and a balance of fiction and nonfiction text) (Officers, 2010). In the Common Core State Standards (CCSS) era, students are expected to appreciate diverse settings and divergent 
cultures, in both the classroom and workplace (Officers, 2010). This key transition asks the classroom teacher to expose students to a balance of genres and story elements. In the Common Core State Initiative English Language Arts introduction, as students advance through the grades, the fulfillment of literate goals include:

They come to understand other perspectives and cultures. Students appreciate that the twenty-first-century classroom and workplace are settings in which people from often widely divergent cultures and who represent diverse experiences and perspectives must learn and work together. Students actively seek to understand other perspectives and cultures through reading and listening, and they are able to communicate effectively with people of varied backgrounds. They evaluate other points of view critically and constructively. Through reading great classic and contemporary works of literature representative of a variety of periods, cul tures, and worldviews, students can vicariously inhabit worlds and have experiences much different than their own.

(Officers, 2010)

A classroom that presents a variety of children's literature in the $21^{\text {st }}$ century classroom is essential for multiple reasons, including fulfillment of state policies and meeting the needs of the diverse classroom. To enhance the teaching possibilities, cognitive and affective factors for all children, an array of diverse literature is non-negotiable in the classroom (Fleer \& Raban, 2005; Kelly \& Moses, 2018; Leu et al., 2003; Mol \& Bus, 2011; NELP, 2008; Serafina \& Moses, 2014).

In addition to the diverse array of literature outlined in the Common Core State Standards (2010), there is a need to create an all-encompassing classroom through a rich and varied supply of children's literature. The International Literacy Association (ILA) advocates for the classroom teacher to set and fulfill high expectations for their students in regards to diversity (ILA, 2018). In 2017, ILA released the Standards for the Preparation of Literacy Professionals 2017. The document sets forth the criteria for developing and evaluating preparation programs for literacy professionals (ILA, 2018); 
wherefore, the Classroom Teachers Matrix by Role put forth clearly defined performance indicators to meet the overarching standards. With a lens placed on the ILA PreK/Primary Classroom Teacher matrix, Standard 4 Diversity and Equity suggests effective practices for culturally responsive instruction.

In addition to the release of the Standards for the Preparation of Literacy Professionals 2017, ILA biennially releases the publication What's Hot in Literacy. The report surveys literacy leaders across the globe to identify literacy matters worthy of discussion, including trending topics and helps propel conversations in the direction where they are needed the most. Top challenges and supports needed by literacy educators and those in the field are also identified and defined. In January 2020, the report identified increasing equity and opportunity for all learners and providing access to high-quality, diverse books and content as two of the top five most critical issues in literacy education, (ILA, 2020). Of the 1,443 survey respondents, $56 \%$ were teachers, $37 \%$ were higher education professionals, $19 \%$ were literacy consultants, and $10 \%$ were pre-k-12 administrators, (ILA, 2020). Of the those surveyed, only $34 \%$ revealed that they felt equipped with the skills needed for effective early reading instruction, (ILA, 2020). Effective early reading instruction includes the usage of children's literature, including interactive reading aloud and shared story book telling that have been proven to improve children's early literacy skills (Mol et 1., 2009). The implications of the 2020 report provide a comprehensive analysis of literacy issues and areas of support that are reflective of literacy professionals.

Over time, as reflected in the ILA's 2020 What's Hot in Literacy report (2020), critical literacy issues and topics vary through time and areas deemed of importance change. As with learning and professional standards, the public school classrooms have considerably transformed. A dramatic societal change, significant shifts in the United 
States population have occurred in the last few decades and it has been suggested that classrooms in the United States are potentially more diverse than anywhere else in the world (Prather, Johnstun, Dyches, \& Johnstun, 2006; Tarbutton, 2018). The population variations have impacted the classroom, including the role of the teacher and the complexity of teaching diverse learners. An emphasis and an expectation to support and foster the development of the 'whole child' are placed upon the teachers in the classroom today (Mihic et al., 2017). To promote an inclusive classroom environment and support the affective domain, children's literature is one powerful tool to address and express diversity. Children deserve a rich and assorted collection of developmentally appropriate books that reflect the many different ethnic, cultural, socioeconomic, and linguistic sources of diversity. Children's literature presents a venue as a way to help children acquire an understanding of cultures, celebrate differences, and foster development of social values (Bishop, 1992). To fulfill this powerful responsibility, it is essential to understand how teachers define diversity and perceive diverse representation in children's literature.

Reflective of the many different ethnic, cultural, socioeconomic, and linguistic sources of diversity is Bronfenbrenner's bioecological model, (Bronfenbrenner \& Morris, 2006). A useful theoretical framework for understanding the unique individual differences among humans is his bioecological model, (Bronfenbrenner, 1994). Based on the idea that relationships and interactions that one has impacts their development, Bronfenbrenner organizes contexts of development into five levels of external influences. The five ecological systems include the microsystem, mesosystem, exosystem, macrosystem, and chronosystem, (Bronfenbrenner \& Morris, 2006). The definitions can 
be accessed for reference in Appendix A, while a full explanatory expansion is presented in Chapter 2.

The $21^{\text {st }}$ century classrooms reflect a diverse group of learners. For this study, aligned with the terminology and intent of the most recent educational and literacy guidelines, it is important to note the researcher's deliberate employment and use of the term diversity. As presented in a comprehensive manner in Chapter 2 and in Appendix A, legislative guidelines and educational policies engage and integrate the term diversity, as compared to multicultural. Multicultural can be narrowly defined to imply ethnicity and race, (Holland \& Mongillo, 2016). A broader term, multicultural may encompass racial and ethnic backgrounds, in addition to a variety of cultural groups (Koss, Johnson, \& Martinex, 2018). Diversity, conversely, is complex, multidimensional, and fluid.

Diversity goes beyond race and ethnicity; the definition encompasses physical and mental disabilities, socioeconomic status, language variations, dialect differences, religion, family structure, as well as sexual and gender identity (Boyd et al., 2015).

\section{Statement of the Problem}

For fulfillment and promotion of an inclusive classroom, the usage of diverse literature in classrooms is vital. As the United States public schools become more diverse and diversity is embedded in educational policies, it is expected that our classroom materials reflect the fluctuating student population. It is essential that educators render conscious decisions about the literature options that their students are exposed to in the classroom (Leahy \& Foley, 2018). To support the varied population that is in the classroom today, teachers have an obligation to reveal diverse conditions and diversity in classroom materials, particularly children's literature. Galda, Cullian, and Sipe (2009) 
imply that literature has the power to expose new worlds and nurture innovative ideas; therefore, literature is a transformation venue to the education of young people.

In the $21^{\text {st }}$ century classroom, teachers are asked to expose their students to a diverse array of literature and support diversity in the classroom to create an inclusive environment (ILA, 2018; Officers, 2010). While educators may elect mindful decisions to fulfill these learning goals and objectives, Leahy and Foley (2018) suggest that there is a general lack of awareness in this field. A content analysis, conducted by Crisp et al. (2016), revealed a need to diversify classroom libraries. Previous studies have established that there is a need for more diverse books to be published. Horning, Lindgren, Schliesman, and Townsend, (2015) reported that across approximately 3,500 books published in 2014 that were received by the Cooperative Children's Book Center (CCBC) at the University of Wisconsin-Madison, only around 11\% contained significant content, topics, characters, and/or themes about African or AfricanAmerican, American Indian, Asian/Pacific or Asian/Pacific American, or Latino or Latino American people. While it is fact that more diverse books need published, Horning, et al. (2016) also report that there is a rise in available children's literature that is diverse in representation.

High-quality children's literature that is diverse in representation is becoming more prevalent, including being recognized as award-winning. The 2015 American Library Association (ALA) Children's and Young Adult Literature awards represented diversity in choices across the awards. In 2016, the ALA awards presented a greater selection of racial and cultural diversity books. The picture book, Last Stop on Market Street (2015), written by a Latino author, Matt de la Pena, with an African American boy as the protagonist, received the Newbery Award. In 2021, two of the most prestigious prizes for children's books, the Newbery and Caldecott, was awarded by the ALA to texts diverse in representation. Given to the author of 
the most distinguished contribution to American literature for children, the 2021 Newbery Medal was When You Trap a Tiger, (Keller, 2020). The text follows a biracial girl whose family moves in with her ailing grandmother. Influenced by her grandmother's Korean folk tales, a magical tiger appears and offers the young girl a deal to restore her grandmother's health. While the Newbery award is given to authors, the Caldecott recognizes the most distinguished American picture book for children. We are Water Protectors, (Lindstrom, 2020), presents watercolor illustrations to tell the story of an Ojibwe girl who joins with other Indigenous people to fight the Dakota Access Pipeline. Over time, accessibility to diverse children's literature is improving.

With that establishment of availability of children's literature diverse in representation, there still remains a need to diversify the contents of classrooms and school libraries (Crisp et al, 2016). Little research has been enacted with attention to representation of diversity in children's literature. Crisp et al.'s research concluded limited diversity of preschool classroom libraries. While this study explored the diversity of children's literature in early childhood classroom libraries, insight into the teachers' definition of diversity, including belief system and perception of diverse representation in children's literature, was not included. Gaining an understanding into teachers' perceptions and representation of diversity could be advantageous in explanation of why classroom libraries remain limited in diverse representation.

While the target focus was use of multicultural literature, not diverse representation in the classroom, Holland and Mongillo (2016) did reveal teacher acuities of literature and how the beliefs of teachers shape perceptions, section, interpretation, and the teaching of multiculturalliterature was completed. The literature review continues to establish and solidify the importance of differentiating the two very similar, yet different, 
terms. Even though Holland and Mongillo's work addressed multicultural literature, it is important to include their work in the establishment of statement of the problem and implications for future research. Their work reveals the need to ask teachers to define the broader diversity definition and their own representation of diversity in children's literature.

The need to explore a teacher's definition of diversity and perception of a diverse representation in children's literature is imperative. Classroom experiences and interactions impact development; therefore, clarity and understanding of how teachers contextualize diversity is essential. It is critical to examine the children's literature that classroom teachers are using to support diversity. Teachers must be familiar with a wide array of children's literature to support the legislative initiatives and diverse classroom population. Children's literature has the potential to reflect society and teachers have a responsibility to expose students to diverse populations through children's literature. With the increased attention on diversity, a critical lens must be placed on how teachers define diversity and their presentation of a diverse representation in children's literature . Previous students have presented results when teachers have been asked to provide a diverse representation of literature to support their diverse community of learners; however, what has not accompanied that question is insight into their perspective of diversity? Preceding research has examined educators' bookshelves for representation of diversity; however, in a limited scope, educators have been asked to present their definition of diversity. There is a need to reveal an analogous understanding of elementary educators' perceptions and representation of diversity. Before further analysis of classroom libraries occur, there is an urgency to step back and ask the parallel 
questions: How do teachers define diversity? And in their classroom, how do teachers represent diversity in children's literature?

\section{Purpose of the Study}

Metaphorically, literature has the potential to serve as windows and mirrors and to offer views of worlds, known and unknown (Bishop, 1993). The reflections and views may become a replication of self and transformation of human experience. Children's literature presents an opportunity for representation of diversity, including the ability for children to see themselves and others in books. The individuals in today's classroom reflect the society shifts and changing communities. More families today live in poverty, speak a primary language other than English, and are ethnically diverse (Prater et al., 2006). The literacy standards and guidelines outline the importance of exposure to rich children's literature. In the field, literacy educators reveal that one barrier to equity in literacy education is a lack of diversity and cultural relevance in literacy resources, (ILA 2020). An additional barrier is variability of teacher knowledge and teaching effectiveness, (ILA). Literacy educators reveal those barriers are also shortcomings; shortcomings in awareness and response to issues related to diversity and/or cultural sensitivities, (ILA). The cognitive and socio-emotional demands of the $21^{\text {st }}$ century require the literacy experience. It is known that the classrooms reflect the diverse population of today's society (Leahy \& Foley, 2018; Prater et al., 2006). With the classroom population shifts and increased focused on diversity, it is imperative to examine how educators perceive diversity, both in conceptualization and representation. How do educators define diversity? How do educators represent diversity in children's literature? Educators' prior knowledge, experiences, and cultural lenses may influence 
pedagogical practices and beliefs. This study presents descriptive case studies of two

elementary educators and their understanding of diversity, both in meaning and in representation in children's literature. 


\section{Chapter II: Literature Review}

In the classroom, children's literature fulfills numerous roles, including read-alouds, mentor texts, introduction of new concepts, and silent reading time. Affective factors, such as motivation to read and fostering a positive attitude about reading, must also be considered in the value of children's literature in the classroom. A balance of fiction and non-fiction texts is an expectation placed on elementary teachers. Using a mirrors and windows pedagogical perspective, children's literature holds the potential to validate and/or devalue a child's role in society, based upon their cultures, identities, or experiences (Bishop, 1990). The American population today is vastly diverse and reflected in classrooms across the country (Leahy \& Foley, 2018). The purpose of this study is to explore how elementary classroom teachers define diversity and their perceptions of diverse representation in children's literature. This literature review presents the value of children's literature in the classroom, conceptualizing diversity and multiculturalism, educational policies and literacy guidelines that embrace diversity, and the changing faces of the American classroom. Next, the theoretical framework sit uates the literature review through a binary combination of theoretical lenses. It is imperative to view the classroom literature representation through the lens of Bishop's (1993) metaphorical notion of books as mirrors, windows, and sliding glass doors, and Bronfenbrenner's (2006) bioecological systems theory.

\section{Legislative Policies}

Literature in the classroom is an essential core of students' education. While it has been demonstrated that children's literature in the classroom has worth for both the cognitive and affective domain, educational learning standards present children's literature as an essential instructional resource as well. There are legislative policies that outline national curriculum 
guidelines that teachers must satisfy to support teaching and learning of all students. Since 2000, there have been several reading reforms efforts and directives that have impacted reading instruction in state and local public-school settings. No Child Left Behind (NCLB) Act of 2001, Reading First (Herlihy et al., 2009), the CCSS for English Language Learners (ELL) (2010), and the ILA Standards for Literacy Professionals (2017) have suggested goals and objectives of the role that children's literature fulfills in the classroom, as well as a supportive tool of diverse classroom populations.

\section{No Child Left Behind (NCLB)}

Enacted by President George W. Bush, the NCLB Act of 2001 was designed to improve student achievement. With the primary goal of providing all children with access to a highquality education, the act was signed into law on January 8, 2002. Four key principles were embodied in the act, including flexibility in federal education funds, accountability systems and an emphasis on teaching methods that have been demonstrated to work (NCLB).

Requirements for the NCLB Act required annual assessments in reading and mathematics. Aligned with the state academic content and learning standards, the state assessments advocated for inclusion. All students who had been in schools in the United States for three consecutive years were required to participate in the state assessments. The inclusionary action mandated that reasonable accommodations for students with disabilitie s or English Language Learners must be made. The NCLB Act supported practices that had been proven to work; therefore, scientifically based reading instruction and programs in the early grades were included under the new Reading First program (NCLB, 2002).

\section{Reading First and Early Reading First}


Created to encourage the utilization of scientifically based reading research, Reading First and Early Reading First was born from the education reform bill, NCLB (2002). NCLB established Reading First as a literacy policy and national program of excellence for all primaryage students in America. In 2002, the Reading First and Early Reading First Initiative was established to promote reading proficiency for all children by the end of third grade (Duggins \& Acosta, 2017; Lyon et al., 2005). While no national curriculum was proposed, the Reading First and Early Reading First initiative was a grant program and funding was provided to schools that implemented effective scientifically based programs and measured results. In the education reform bill, an emphasis was placed on early childhood programs to support the early cognitive domain and language development of early learners. To prevent reading difficulties, Reading First and Early Reading First programs mandates included activities that promoted oral language and a literacy-rich classroom (United States Department of Education [USDE], 2002). Numerous guidelines to fulfill and promote reading success were outlined, including those that promoted the utilization of literature. Reading Is Fundamental (RIF)-Inexpensive Book Distribution Program, promoting school libraries, and motivation incentives to read books were several activities defined in the educational reform bill. While an encouragement of literature was stated in the Reading First and Early Reading First legislation, what is important to be noted is that direction on range of genre, content, and complexity of the literature was not delineated in the policies. After a NCLB critical content analysis, Garcia and Wiese (2009) recommended that as the United States advances in educational policy, a lens must be placed upon the ever-increasing diversified classroom population. Included in their research recommendations and implications for the classroom was that educational policies take into the importance the dramatic shifts in technology, globalization, and democratization (Garcia \& Wiese, 2009). Citing the imperative 
need to foster equality and support a range of learners, educational policy must take this into account in the reform design. The Reading First and Early Reading First legislation required scientifically based reading research practices and placed an emphasis on early reading and increased book reading.

\section{Common Core State Standards for English Language Arts}

While the NCLB reform bill, including Reading First and Early Reading First legislation, positioned reading instruction based upon scientific research, including an increase in book access and early reading, the CCSS for English Language Learners (ELA) impacted the role of literature in the classroom, including exposure to a literature that includes a range of complexity, quality, and range.

In 2009, the United States Emergence of the CCSS commenced after the NCLB legislation. The CCSS ELA influenced the utilization and interaction with literature in the classroom. While its predecessor, Reading First, supported instructional practices with curricula materials, including the use of highly scripted materials, (Beck, 2010; Gamse et al., 2008; Pearson, 2010), the CCSS ELA advertised teacher autonomy in how to teach the standards. The CCSS ELA encouraged a breadth of literature and range of content, genre, and complexity. To support teachers' instructional approach in fulfillment of the standards, an appendix of text exemplars and a Publisher's Guide was released,(revised 2012). Presented in Appendix B of CCSS (CCSS; National Governor's Association Center for Best Practices [NGA Center] \& Council of Chief State School Officers [CCSSO], 2010), were suggested samples of grade-level text complexity and quality. Unlike the Reading First and Early Reading initiatives, text exemplars were presented as samples and suggested fidelity of the standards. While the introduction to Appendix B recommends breadth of text types that students should encounter as 
required by the standards, including a variety of culturally diverse literature, content analysis of Appendix B suggests differently. Boyd et. al (2015) examined the text exemplars and found that more literature from the literary canon was included and far less contemporary diverse selections. Of the suggestions for grades 4-5, thirty-one text examples are given. Boyd et. al (2015) revealed that of those:

- 5 books had significant African American content

- 3 authors are African American

- 1 author is Guyanese

- 2 books had significant American Indian content

- 1 author is Native American

- 1 book had significant Asian/Pacific Islander content

- 1 author is Asian/Pacific Island American

- 1 book had significant Latino/Latina content

- 2 authors are Latino/Latina

Their work reveals that while the text exemplars in Appendix B recommends culturally diverse authors' work for $4^{\text {th }}$ and $5^{\text {th }}$ grade students, it is critical for educators to seek additional and varied resources to reflect the diverse and complex society in which we live.

\section{International Literacy Association 2017 Standards for Literacy Professionals}

A reflection of the diverse and complex society is represented in the school system. As a diverse population comprise the classroom, the International Literacy Association (ILA) 2017 Standards for Literacy Professionals promoted a greater advocacy on learners with varied cultural, linguistic, and racial backgrounds. An international professional organization with a mission to promote reading through the advancement of quality literacy instruction and research, ILA provides guidance on research-based literacy practices (ILA, 2020). Developed by literacy experts, the ILA 2017 standards address the increasing need for a broader definition of literacy, 
one that embraces reading, writing, speaking, listening, viewing, and visually representing in both print and digital spaces (ILA, 2020). In the 2017 standards, diversity is defined as:

“ethnicity, race, socioeconomic status, gender, learning exceptionalities, geographical area, physical abilities, language, religion, sexual orientation, and political affiliations and other ideologies (ILA, 2018)."

For the classroom teacher, the 2017 standards outline explicit expectations in the knowledge to effectively respect and teach the diverse students in schools. The Diversity and Equity Standards emphasizes all forms of diversity are acknowledged and respected in the schools (ILA, 2018).

Underlining the Diversity and Equity Standard is the research-based need to create curriculum that respects diversity and requires one to be aware of their personal belief system to best understand the value of other groups' experiences, beliefs, identities, and practices (ILA, 2018). The ILA 2017 standards advocate that the classroom teacher supports the diverse classroom population by creating an inclusive environment that respects individuals from different backgrounds and embraces diversity.

\section{ILA Standards for the Preparation of Literacy Professionals 2017 Standard 4}

The ILA Standards for the Preparation of Literacy Professionals 2017 titles Standard 4

Diversity and Equity (ILA, 2017). Standards for varying literacy roles are elaborated and extended upon in different matrixes. As this study is exploring the elementary teacher's perception and representation of diversity, the PreK/Primary Classroom Teacher Matrix was employed (ILA, 2017). As presented, Standard 4 examines diversity and equity, (ILA, 2017):

Standard 4: Diversity and Equity:

Candidates demonstrate knowledge of research, relevant theories, pedagogies, and essential concepts of diversity and equity; demonstrate an understanding of themselves and others as cultural beings; create classrooms and schools that are inclusive and affirming; advocate for equity at school, district, and community levels. 
Within Standard 4, four components are presented to elaborate on the responsibilities of the classroom teacher in regard to diversity and equity (ILA, 2017):

- 4.1: Candidates recognize how their own cultural experiences affect instruction and appreciate the diversity of their students, families, and communities

- 4.2: Candidates set high expectations for learners and implement instructional practices that are responsive to students' diversity

- 4.3: Candidates situate diversity as a core asset in instructional planning, teaching, and selecting texts and materials

- 4.4: Candidates forge family, community, and school relationships to enhance students' literacy learning

\section{What's Hot in Literacy Report, International Literacy Report}

Currently a biennial publication, the ILA's What's Hot in Literacy Report provides suggestions on critical topics and issues in literacy education. First published in 1997, the report was available only in the members-only newspaper of the International Reading Association (IRA), now the ILA, (ILA 2020). Originally, the sample population was approximately 25 literacy leaders. The survey identified literacy topics noted of importance by the respondents. By 2001, the questions "What should be hot?" and "What shouldn't be hot?" were included in the survey, (ILA, 2020). The addition of the questions provided a more thorough depiction of what the important topics in reading and writing instruction should be and what direction the conversation in literacy education needed to be. In 2017, ILA redesigned the survey with a broader outreach of respondents nearly 1,600 (ILA, 2020). In 2018, ILA created a collaborative partnership with YouGov, a global market research firm, to more efficiently manage and report the survey. This collaboration resulted in a biennale publication. The ILA 2020 What's Hot in Literacy report received input from 1,443 literacy professionals from 65 countries and territories, (ILA, 2020). The findings present what they deem as important issues worthy of discussion and critical topics for advancing literacy instruction worldwide. As reported in the ILA's 2020 
What's Hot in Literacy report, issues critical of discussion and advancing literacy instruction that were consistently chosen as a top 5 topic from those surveyed include:

- Increasing equity and opportunity for all learners

- Providing access to high-quality, diverse books and content

- Fostering social-emotional competencies through literacy instruction

- Leveraging literacy as a pathway to social justice

- Creating a culturally responsive environment

Additionally, the report reveals several barriers to equity in literacy education, including:

- $\quad 57 \%$ report variability of teacher knowledge and teacher effectiveness; differences in teacher preparation programs are cited

- $44 \%$ report lack of awareness of instructors' implicit biases

- $42 \%$ report lack of diversity and cultural relevance in literacy resources

- $42 \%$ report lack of culturally responsiveness in literacy instruction

- $40 \%$ report lack of diversity within the teacher population

As the percentages reveal, educators are aware of the need to provide high-quality and diverse books for all learners; however, full resolution has not occurred. In this biennial report, literacy educators identify what they deem as essential in advancing the literacy professional and instruction. One goal of the survey is to foster critical conversations in literacy. As identified, there is a need to explore views and representation of diversity in the classroom. Seeking insight into teachers' perceptions and ideas of diversity and diverse representation of children's literature may bridge that gap.

\section{Classroom Population}

In consideration of the diverse and complex society in which we live, multiple stories and complex development systems are intertwined in the classroom. In the United States public schools, the classrooms project a diverse scenery of students. Classrooms in the United States present the possibility of potentially being more diverse than any where in the world (Tarbutton, 2018). Movement towards full inclusion, poverty, and the high number of immigrants are several 
influential factors for diversity in the classroom. According to Portney et al., (2015), America receives more than a million legal immigrants annually. The National Center for Education Statistics (2019) report:

In Fall 2016, 9.6 percent, or 4.9 million, of public-school students in the United States were English Language Learners (ELL)

In $2017,26.3 \%$ of children under age 18 living in mother-only households

In $2017,18 \%$ of children under age 18 in families living in poverty

In $2017-2018,14 \%$ of public-school students ages 3-21 receiving special education services.

When viewing the classroom population through identity categories represented, it is important to note that economic and/or racial segregation is still present in the United States. In a study completed by Boser and Baffour, (2017), it was found that $40 \%$ of the school districts in their sample were hypersegregated by income. The Economic Policy Institute reported that black children are five times as likely as white child to attend schools that are highly segregated by race and ethnicity, (Carnoy \& García, 2017). This information continues to reinforce the need for integration in the classroom. Addressing the diverse needs and backgrounds of all students is a best practice that educators should embrace. Diverse classrooms present the opportunity to mirror reality, present multiple perspectives on issues, and interpretation of content.

\section{Diversity Defined}

What is diversity? Its message is beguilingly simple and effective. Humans come in a variety of formats - with differing genders, skin tones, hair color and types, eye shapes, and sizes in the realm of physical differences, and diverse languages, religions, nationalities, and lifestyles in the realm of social differences. While diversity acknowledges the unique identity of such peoples, it also stresses that despite differences, we are all the same - that is, we are all humans with equal rights and privileges. (Davis, 2015)

In consideration of classroom population, engagement with text, and academic guidelines, it is essential to define diversity. Describing and defining diversity can be broad, all 
encompassing, and complicated. Exposure to and interaction with text influences readers, both emotionally and cognitively. Legislation policies and curricular guidelines expect elementary educators to present a wide range of text, including increased complexity, varied formats, and multiple genres. To clarify the research, the academic guidelines, engagement with texts, and classroom population it is essential to define diversity. AllSides Red Blue Dictionary (2019) presents diversity as the range of differences in human experiences. The Encyclopedia of Diversity and Social Justice situates human diversity as the variety of differences that exist among the human differences (Thompson \& Cusseo, 2014). Merriam-Webster(2020) defines diversity as being composed of different elements and/or the condition of differing qualities. Cambridge Dictionary (2020) describes diversity as a range of different people; including a mixture of races and religions that make up a group of people. The sources of diversity include, (not limited to): social, physical, and emotional development, gender, language, cultural, religious, and ethnic identity, socioeconomic status, and sexual orientation (Tarbutton, 2018). Hermann-Wilmarth (2007) and Boyd et al. (2015) advocate for diversity in literature to expand beyond race, ethnicity, and language. It is recommended that diversity characteristics in literature should also include various family structures, physical and mental disabilities, socioeconomic status, language variations, dialect differences, and language variations (Boyd et al., 2015).

\section{Diversity versus Multiculturalism}

While the terms may be confused as interchangeable, there is a difference in the definition and implications in the terms, diversity and multiculturalism. For this study, it is essential to differentiate the terms that are often substituted and used synonymously with one another. As presented, diversity references a state of unlikeness and the manner in which all of the ways in which people are different, including individual, group, and cultural differences. 
While diversity includes the broad range and acceptance of all the ways humans are different, multiculturalism can be narrowly defined to mean ethnicity and race, (Holland \& Mongillo, 2016). A dictionary definition presents multiculturalism as the presence of, or support for the presence of, several distinct cultural or ethnic groups within a society...cultural pluralism," (Merriam-Webster, 2020). In regard to multicultural literature, it can be defined as literature that focuses on people of color from diverse cultural, linguistic, and religious groups (Yokota, 2001). Our nation's classrooms are reflective of our diverse population. As The IRIS Center (2012) presents, it is important to recognize and honor student diversity in the classroom; this acknowledgement embraces and includes different races, cultures, ethnicities, linguistic differences, socioeconomic backgrounds, a range of academic, physical, and social abilities and skills (The IRIS Center, 2012). As reflective in educational policies and guidelines, it is important that classroom teachers accept and recognize diversity in the classroom.

\section{The Value of Children's Literature in the Classroom}

In the classroom, children's literature is an essential resource and fulfills multiple roles, including the support of the cognitive and affective domain. For some young children, the classroom setting is the first/only exposure to children's literature. The influential interaction of children's literature, whether it exclusively occurs in the classroom or not, is one of great significance. When viewed through the theoretical concept that books may act as mirrors, windows, and sliding glass doors, (Bishop, 1990), stories share may present a vicarious experience that may represent reality or distortion of reality, as well as observation and insight into other worlds. Children's literature presents the foundational support platform for the development of young readers, the promotion of readers, storytelling, comprehension, vocabulary, and exposure to new concepts and ideas (Serafina \& Moses, 2014). Research has 
demonstrated that due to the varied and multiple benefits, children's literature in the classroom must not be utilized as a luxury; rather, a necessity in the literacy curriculum (Leu et al., 2003). Across the domains and curriculum, there is a great value on the importance of children's literature in the classroom.

Bloom (1956) describes the cognitive domain as learning of new knowledge, concepts, and mental skills, including comprehension and application. Commonly referred to as Bloom's Taxonomy of the Cognitive Domain, the levels within in the cognitive hierarchy range include knowledge, comprehension, application, analysis, synthesis, and evaluation. Literacy skills, vocabulary exposure, content area concepts, writing styles, and print concepts include just a few of the cognitive services fostered by children's literature. Critical thinking skills are developed through the use of children's literature. Through meaningful discussions, children's literature may spark inferential discussion and develop listening and speaking skills (Kelly \& Moses, 2018). In 2011, Lefebre, Trudeau, and Sutton found that children involved in shared read-alouds outperformed their peers on vocabulary, print awareness, and phonological awareness measures. Numerous studies have presented evidence that reading aloud has the potential to increase the oral language abilities of young children and be a factor in sustained literacy growth and achievement (Beauchat et a., 2009; Diehl \& Vaughn, 2010; Lefebvre et al., 2011). The connections between children's literature and the cognitive domain are highly valuable and nonnegotiable.

The value of children's literature in the classroom has been well documented to support the cognitive domain; however, children's literature in the classroom has been shown to effectively support the affective domain as well. While Bloom (1956) categorized knowledge in the cognitive domain, he presented the affective domain as feelings, emotions, and attitudes. 
Children's literature presents an opportunity to promote a love of reading, motivation, empathy, and a sense of community. Through interactive discussions, read-alouds, and independent reading, children's literature can be a venue for building a cohort of learners through social interactions (Bridges, 1995). A sense of empathy for other people and an understanding of self can be developed through children's literature. Children's literature provides a platform for vicarious experiences, a reflection of reality, self, and narratives of places and people that they are unaware of and/or have not experienced. An understanding of self and increased self-esteem can occur when children read stories about children like themselves; a connection to the literature is established and it may normalize experiences that may otherwise be isolating (Lea, 2015). A yearlong collaborative study with first-grade students found that discussions based around literature presented multiple opportunities to address social injustices, share life experiences, and express compassion and empathy (Kelly et al., 2019). Read-alouds, independent reading, and meaningful conversations about children's literature supports growth and knowledge gained in both the cognitive and affective domain.

\section{The Diversity of Children's Literature in Early Childhood Classroom Libraries}

The examination of diverse children's literature on bookshelves has had limited analysis. The Crisp et al. (2016) research involved classrooms spanning across eleven early childhood sites and predominantly served low-income, racially diverse (but predominantly African American) populations. Nearly all of the teachers identified themselves as African American females. At various points during the fall and early winter months, the research team visited the locations and scanned the barcodes of all of the books. Information from Goodreads and the Library of Congress allowed the researchers to create a centralized database. An examination of preschool classroom libraries with attention to representation of diversity populations and 
identities, the results revealed that the classroom libraries were lacking in terms of cultural diversity. Little diversity in languages, members of parallel cultures, depictions of class and socioeconomic status, characters with dis/abilities, developmental differences, and chronic illnesses were found. The greatest diversity was found in representation of gender; however, there was nearly double the number of male representations as compared to female, with even fewer ungendered depictions and no representations of transidentified people (Crisp et al). From their research, Crisp et al. suggested the need to constantly evaluate the contents of the classroom books, based upon the ever-changing cultural issues, relationships, languages and change across time.

\section{Elementary Teachers' Perspectives on the Use of Multicultural Literature in their}

\section{Classrooms}

As limited research has explored teachers' perspectives on their perspective and representation of diversity, it is important to include Holland and Mongillo's (2016) work. They sought to determine how multicultural literature was used and perceived by US elementary school teachers. In addition to use, how the beliefs of teachers shaped perceptions, selection, interpretation, and teaching of multicultural literature was explored. Using a qualitative web survey design, twenty-six elementary school teachers completed an online survey. In a set of fifteen questions, participants were asked questions that reflected their background, the school and district resources, the teacher's perspectives and practices of how multicultural literature was used, (definition, topic sensitivity, access to multicultural literature, student ethnicity, and identification of how selected multicultural book titles reflected issues of multicultural sensitivity ). Data were analyzed using constant comparison methods, including direct quotes to confirm findings 
of emerging themes and patterns. From their work, Holland and Mongillo's (2016)

findings included:

- Strong support for multicultural education by elementary administrators encourages reading of multicultural literature in the schools

- Mandating multicultural literature does not always increase the reading of multicultural literature in elementary schools

- Administrators involved with mandates may limit the use of multicultural literature by promoting close adherence to curriculum for multicultural literature selections

The findings emphasize the importance of the theoretical underpinnings that all students must see themselves in the books they are reading; therefore, the importance of diverse representation in children's literature. The findings also reveal the role that prior experience, specifically at the preservice teacher level, plays in one's development and conceptualization of diversity. While the research concludes the importance of the administrators to promote multicultural literature, it provided insight that teachers may feel uneasy using books that they deem as unfamiliar and/or unknown to them (Holland \& Mongillo, 2016). The study expanded on the need that teachers understand the components of multicultural literature in the broader term and they increase their use of high-quality, authentic multicultural literature in their classrooms.

Additional research has been done to reveal a teacher's perception of diversity in children's literature; however, those studies did not give insight into teachers' definition of diversity. In a study that asked teachers to identify two children's books from five different ethnic groups, Brinson (2012) discovered that the majority of the sixty-one participants could only identify two books from the Anglo-American category and lacked book knowledge in all other cultural areas. Patt \& McBride (1993) conducted an exploratory study of gender equity in picture books. In their research, they asked elementary teachers to name their favorite books to read aloud and only $21 \%$ of the books contained female protagonists (Patt \& McBride, 1993). In 
a study that explored the disparities of the awareness of teachers in a special education

framework to use books as a mediating tool, Baratz (2015) found that teachers did not regularly place effort to use diverse literature as a tool. Boyd, Causey, and Galda (2015) have found that culturally diverse literature in classrooms is delivered when teachers make it happen.

\section{Theoretical Framework}

To gain insight into teachers' thoughts and perceptions of diversity in the classroom, this study is enclosed in a dual theoretical perspective to create a coherent, conducive framework. Through the lens of Bishop's (1993) metaphorical notion of books as mirrors, windows, and sliding glass doors and Bronfenbrenner's (2006) bioecological systems theory, this research is built upon the notion that teachers' perceptions of diversity is influenced by prior experiences, relationships, and interactions; therefore, in the classroom, exposure to children's literature must allow for multiple stories and perspectives to be shared. This approach allowed the researcher to look at the study in relationship to the teacher's definition of diversity and the literature that they identified diverse in representation. This was important for two reasons. First, it provided the researcher with information on how background knowledge and life experiences, including their teacher preparation program, influenced their perception of diversity in a classroom setting. Second, it situated literature as a transformative venue in which diversity can be represented. In today's diverse classroom, teachers' perceptions of diversity matters. If educational policies and guidelines recommend supporting diversity in the classroom, it is imperative that insight into teachers' conceptualization and representation of diversity is considered. The multiple lenses that this research is situated in provides an opportunity to consider the bidirectional interactions within one's ecological contexts and the influence those interactions have on a teacher's perception of diversity. 


\section{Bishop's (1993) metaphorical notion of books as mirrors, windows, and sliding glass}

doors.

While the completeness of a reader can be achieved through literary experiences, children's literature may also provide an opportunity for students to identify with and/or see them reflected. Placing a pedagogical and theoretical lens on this research, it is helpful to understand Dr. Rudine Sims Bishop's (1990a) metaphorical idea that books may serve as windows, mirrors, and sliding glass doors for children:

Books are sometimes windows, offering views of worlds that may be real or imagined, familiar or strange. These windows are also sliding glass doors, and readers have only to walk through in imagination to become part of whatever world has been created and recreated by the author. When lighting conditions are just right, however, a window can also be a mirror. Literature transforms human experience and reflects it back to us, and in that reflection, we can see our own lives and experiences as part of the larger human experience. Reading, then, becomes a means of self-affirmation, and readers often seek their mirrors in books. (p. ix)

When using children's literature in the classroom, the consideration of a windows, mirrors, and sliding glass door perspective promotes the importance of purposeful and considerate diverse representation. This conceptual framework is connected to this research as it promotes the power and influence that children's literature conveys. The concept that books may serve as a means for readers to see themselves in the text and may provide a connection to portions of their identities, culture, and/or experiences is critical in what children's literature is provided in the classroom. Contingent upon the text, children may see a distorted reality if they are not able to find themselves in the text; therefore, not validated and impacting the optimal achievement level. Bishop (1990b) advocates that children's literature is an important socialization agent and provides them with information about their societal and cultural values, including acceptable and appropriate behaviors. Bishop encourages the use of children's literature as a means to provide children with experiences that value the reader, that children have the right to be exposed to 
books that reflect their world, and books that expose fewer familiar worlds (Bishop, 2012). It is appropriate for this study as it allows for a deeper insight and analysis into the children's literature that educators are using to support diversity in the classroom. From this standpoint, it positions the research in how children see themselves in children's literature and how children's literature mirrors the world. This is important as it intentionally positions the text as central to children's lives and to the classroom experience.

\section{Bronfenbrenner's (1994) Bioecological Model}

A framework that one can examine of individuals' relationship within communities and wider societies, Bronfenbrenner's (1979) bioecological systems theory presents a theory of human development. An evolving theoretical system, the bioecological model describes development as phenomenon of continuity and change in the biopsychological characteristics of human beings, (Bronfenbrenner \& Morris, 2006). First proposed in the 1970s, the emerging theory was described as an ecological model/approach to human development, (Rosa \& Tudge, 2013). This model was first used in the world of human development with an emphasis on the role that the environment played in an individual's development, including all the intrinsically interconnected structures. Bronfenbrenner's primary theoretical contribution was his Ecological Systems Theory (Bronfenbrenner, 1977), in which he described four types of nested systems. He called these the microsystem, the mesosystem, the exosystem, and the macro-system. Bronfenbrenner later added a fifth system, called the chronosystem (1979). The nested five ecological systems were arranged to demonstrate the order of impact that each structure had on an individual's development. The conceived environment topologically was arranged of five connected configurations, (Rosa \& Tudge, 2013):

Microsystem: The most proximal setting in which a person is situated; Examples include the home, child care, playground, place of work et al... The setting allowed for 
interactions that are face-to-face and have interpersonal roles and relations that are engage in over time

Mesosystem: A system of microsystems; Active participation in a new setting and diminishes when the individual leaves; Examples include the interactions between a child's parents and teachers

Exosystem: The developing individual is not an active participant nor situated; never less, experiences its influences; Examples include mass media, the individual's neighborhood

Macrosystem: Embraces the institutional systems of a culture or subculture; an overarching belief system; Examples include ethnicity, geographic location and ideologies of the culture

Chronosystem: The overarching system; normative and nonnormative life transitions, including sociohistorical events; Examples include marriage, divorce, winning the lottery.

As the theory continued to evolve, Bronfenbrenner revised his theory in 1994 and named it the Bioecological Model (Bronfenbrenner, 1994). His focus shifted from environmental influences to developmental processes individuals experience over time. Bronfenbrenner emphasized the role played by an individual in their own development by proximal processes; the center of the bioecological theory and viewed as the driving forces of human development, (Rosa \& Tudge, 2013). Proximal process may include relationships among people, relationships between people and symbols/objects they encounter. The bioecological systems theory presents an understanding of how an individual grows and develop. The ecological journey that one embarks on varies from one individual to the next. An individual's interactions within a series of larger systematic influences has an impact on human development and growth. This theoretical approach highlights the importance of an individual's relationships and prior experiences. An exploration of an individual's systems provides a holistic approach to their development, including a contextual setting, values, ideologies, and personal characteristics. When seeking insight into a teacher's conceptualization and representation of diversity in the classroom setting, 
the bioecological systems model provides reveals multiple layers of an individual's knowledge of the world, including diversity (Kemmerlin \& Wilkins, 2020).

\section{Binary Theoretical Framework}

Using a binary theoretical framework to situate the research, through the lens of Bishop's (1993) metaphorical notion of books as mirrors, windows, and sliding glass doors and Bronfenbrenner's bioecological model (1994), places the study in a position to examine the environmental framework of the teacher and children's literature as an influential entity in the classroom. In consideration of the legislative policies and educational guidelines that encourage a range of text and the diverse classroom population that is representative in the United States public school system, this framework captures the perspective of the teacher, in regard to diversity. The dual lenses intentionally position a teacher's understanding of diversity as pivotal to students' exposure to children's literature. It is critical to look at how teachers are using children's literature to support diversity in the classroom and the content of that text to determine the narratives that are represented. Bishop (1990a) introduced the idea of the purposeful selection in books to be shared in the classroom that help children validate themselves and understand the world around them. Bronfenbrenner's bioecological model allows for an understanding of the external influences on human behavior and development, including the role of subjective experiences, (Kemmerlin \& Wilkins, 2020). Through the dual lenses, the theoretical framework places the role of children's literature in the classroom vital in forming a more nuanced picture of the world; one that genuinely reflects the diverse classroom population. 


\section{Chapter III: Method}

The purpose of this chapter is to introduce the qualitative research design that will be employed in this study. This approach allows for a deeper understanding of how teachers conceptualize diversity, in definition and in representation in children's literature. Through the lens of a descriptive case study approach, interviews collected data from two elementary educators to gain insight into their perception of diversity. To reveal how they feel diversity is represented in children's literature, a content analysis of the identified texts was completed.

\section{Research Questions}

This study focuses on the following research questions:

RQ1: How do teachers define diversity?

RQ2: What children's literature do they consider is diverse in representation?

\section{Participants and Context}

The sample was drawn from two different elementary schools, located within the same school district, in the Northeast United States. The criteria for participant selection was employment as an elementary educator (pre-kindergarten through grade 5) that teaches in a general education classroom. As this study was viewed through the lens of Bishop's (1993) metaphorical notion of books as mirrors, windows, and sliding glass doors and Bronfenbrenner's bioecological model, a purposive sample was employed to identify participant selection. The main goal of a purposive sample is to produce a sample that is representative of the population (Lavrakas, 2008). Specifically, due to location of researcher, it was most convenient to focus on elementary teachers in a rural school setting. After gaining Institutional Review Board (IRB) approval and permission from the building principal, requests to participate in the study were electronically delivered to all of the teachers in the building and the first two respondents were accepted, per research criteria guidelines. The researcher obtained informed consent from the 
participants, in addition to an email address. IRB Teachers were asked to use only a first name pseudonym. For identification on questionnaires and transcripts, each teacher was assigned a number. Table 1 presents the demographic characteristics of Teacher 1 and Teacher 2 . As the goal of the study is to gain insight into teachers' perceptions of diversity and representation of diversity in children's literature, the primary reason for the school location was proximity within the researcher's existing professional network.

\section{Table 1}

Demographics Characteristics of Each Participants

$\begin{array}{lll}\text { Demographic } & \text { Teacher } 1 & \text { Teacher } 2\end{array}$

\begin{tabular}{|c|c|c|}
\hline Gender identification & $\begin{array}{l}\text { Cisfemale/ciswoman } \\
\text { a person whose } \\
\text { gender identity } \\
\text { corresponds with the } \\
\text { sex the person was } \\
\text { identified as having at } \\
\text { birth }\end{array}$ & Cisfemale/ciswoman \\
\hline Ethnicity & White & White \\
\hline $\begin{array}{l}\text { Current grade } \\
\text { teaching }\end{array}$ & $\begin{array}{l}4^{\text {th }} \text { grade general } \\
\text { education classroom }\end{array}$ & $\begin{array}{l}1^{\text {st }} \text { grade general } \\
\text { education classroom }\end{array}$ \\
\hline $\begin{array}{l}\text { Years teaching at } \\
\text { current school }\end{array}$ & 4 years & 12 years \\
\hline Total years teaching & 8 years & 17 years \\
\hline Highest completed & Bachelors & Masters \\
\hline
\end{tabular}


education level

\section{Community Setting}

Both of the respondents taught within the same school district; however, at two different elementary schools. The school district is located in a small suburban area, with the closest metropolitan area an hour away. There are close to 5,000 students enrolled county-wide and nearly 400 teachers employed full-time, (National Center for Education Statistics, n.d.). Countywide, the median household income is nearly $\$ 44,000$ and race/ethnicity is $97 \%$ white (National Center for Education Statistics, n.d.).

\section{Methodology Selected}

To fulfill the goals of the study, a descriptive case study was the most appropriate. Qualitative research seeks to understand the participant's perception in a naturalistic setting (Mills \& Gay, 2019). Because this research sought to gain understanding in how teachers perceive diversity and conceptualize diversity represented in children's literature, a case study research design allowed the researcher to focus on a unit of study (i.e., elementary educators) (Mills \& Gay, 2019). Research questions that address what and how provide the researcher with a foundational starting platform. Aligned to the characteristics of case study research design, the determination of the binary theoretical framework was establis hed prior to the commencement of the research (Mills \& Gay, 2019). To understand how a teacher defines diversity, Bronfenbrenner's (1994) bioecological model provides a useful framework that contextualizes influential factors and interactions that influence one's development. The bidirectional nature of interactions within the various ecological contexts demonstrates that values and ideas can be disseminated from various sources, including institutions to individuals and individuals to institutions (Kemmerlin \& Wilkins, 2020). The transformational nature of children's literature is 
supported in Bishop's (1993) concept of mirrors, windows, and sliding glass doors; therefore, that implication emphasizes the incredible power of the messages and stories that are being shared in the classroom.

\section{Data Sources}

To collect the data for both RQ1 and RQ2, a semi-structured interview and a questionnaire was delivered and recorded. Through a recorded interview, the researcher utilized the interview guide as an instrument to start the conversation about perceptions of diversity, both in meaning and in children's literature. Each participant completed a questionnaire independently. Guided by Bronfenbrenner's (1994) bioecological model, Appendix B presents the interview guide and Appendix $\mathrm{C}$ presents the questionnaire. The interview was recorded via an electronic source. The questionnaire was completed privately by each participant. Next, the transcripts from both interviews permitted the researcher an opportunity for an in-depth analysis.

\section{Instrument Design}

As the main goal was to gain insight on how teachers define diversity and perceive diverse representation in children's literature, to collect the data for RQ1 and RQ2, a questionnaire and semi-structured interview was designed. This questionnaire was delivered and independently completed electronically by the research participants. Guided by Mills and Gay (2019), the questionnaire is short, brief, and easy to respond to. Mills \& Gay (2019) define an interview as an instrument that is used to collect data and is completed orally, in-person, question-and-answer session between a researcher and an individual. A semi-structured interview allows for a blend of closed- and open-ended questions, typically followed up with how and why questions (Adams, 2015). As a valid and reliable survey interview guide was not available, the researcher developed one to ask the appropriate questions and engage in 
discussion. This approach is quite common as the researcher is seeking information that is not already available (Mills \& Gay, 2019). The formulated questions were influenced by Holland and Mongillo's research (2016), the dual theoretical framework of Bishop's (1993) metaphorical notion of books as mirrors, windows, and sliding glass doors and Bronfenbrenner's bioecological model (1994), and The ILA Standards for the Preparation of Literacy Professionals 2017 titles Standard 4 Diversity and Equity, (ILA, 2017). Using guidelines for constructing survey research (Mills \& Gay), the researcher developed an agenda for the interview guide to collect teachers' perspectives of diversity and representation in children's literature. As the researcher sought an understanding of teachers' conceptualization and representation of diversity, a semi-structured interview format encouraged depth in responses. For the most authentic and valid instrument, the researcher created the interview guide based upon the following guidelines, (Mills \& Gay, 2019):

- Include only items that relate to the objectives of the study

- Focus each question on a single concept

- Make the questionnaire brief

- Know what information you need and why

Appendix D presents the theoretical framework alignment to instrument design crosswalk. Analysis of RQ1 Data

This case study collected data through the employment of a recorded semi-structure interview and analysis through a two-step cycle coding process. To analyze the findings of RQ1 data, descriptive coding (Saldana, 2012) was applied in the first cycle of coding. For the first cycle of coding, In Vivo coding, allowed the researcher to use words and short phrases directly from the interviews in the data record as codes (Miles et al, 2014). In the first coding cycle, direct phrases and words will be categorized in alignment with The ILA Standards for the 
Preparation of Literacy Professionals 2017 Standard 4 Diversity and Equity, (ILA, 2017).

Appendix E presents the matrix that was utilized. As this study explored the elementary teacher's perception and representation of diversity, the PreK/Primary Classroom Teacher Matrix was employed, (ILA, 2017). This approach provided a means of reliability and validity as the ILA'S 2017 Standards for Literacy Professionals Standard 4 Diversity and Equity Standards outlines guidelines and best practices for literacy professionals and educators in the classroom. This approach honored the participant's voice with direct quotes to be aligned to educational policies that outline diversity.

While the first cycle employed an In Vivo coding method, focused coding as a second cycle method allowed for the researcher to categorize the data based upon Bronfenbrenner's 1994 bioecological model, (Appendix F). For this study, to increase reliability and validity, it was most appropriate for the researcher to employ a second cycle coding method. The second cycle coding method allowed for the data to be analyzed from information that informed the literature review and the dual theoretical framework that situates the study (Onwuegbuzie, 2016). Categories that emerged from the first cycle In Vivo coding was followed by a focused coding approach. This method focused the data analysis by classifying data based upon the Bronfenbrenner's bioecological model. This approach permitted the researcher to integrate the theoretical framework while analyzing the data. The first cycle of In Vivo coding permitted the researcher to create codes based upon literacy initiatives that places expectations on the classroom teacher to demonstrate awareness and respect of diversity. The second cycle focused coding approach allowed the researcher to frame the study to show the developmental impact influenced by proximal processes and interactions of one's environment, (Bronfenbrenner). 


\section{Content Analysis of RQ2 Data}

A qualitative content analysis permitted the researcher to organize and deduce meaning from the collected data and derive realistic conclusions from it (Bengtsson, 2016). For this conventional content analysis, the review started with a priori codes. The researcher acknowledged that additional codes may emerge. The review in this study was an exploration and categorization of the identified children's literature texts, (as identified in the semi-structured interview). This approach enabled the researcher to categorize the children's literature based upon an instrument utilized in work done by Crisp et al, (2016). This approach made sense as it aligned with Bishop's idea (1993) that children's literature serves as mirrors, windows, and sliding glass doors and identity representation is essential in the classroom. As Crisp et al, (2016), categorized in their work that identified diversity of children's literature in early childhood classroom libraries, the texts were coded as including explicit depictions of various cultural identities; representations of identity categories were:

\section{Figure 2}

\section{Diversity Representation Categories and Meanings}

- Parallel cultures

- Socioeconomic status and class

- Dis/abilities, developmental differences, and chronic illnesses

- Sexual identity

- Religion

- Gender

Seeking to make sense of the selection of children's literature that was identified as diverse in representation, a conventional content analysis allowed the researcher to provide a systematic and objective means to make valid inferences from the data to describe the particular phenomena (Bengtsson, 2016). A conventional content analysis is most appropriate as it allows 
the researcher to present the data in words and themes; therefore, allows an interpretation of the results (Bengtsson, 2016). Going above and beyond counting words, qualitative conventional content analysis allows for intense examination of language for the purpose of classification and to provide understanding of the phenomenon under study (Hsui-Fang \& Shannon, 2005). As completed by Crisp et al, (2016), when coding books for depiction of the identified categories, the researcher relied exclusively on the primary text and the peritextual content. As outlined in educational policy, a balance of genres, complexity, and range are suggested as a means to provide depth and breadth to students in the classrooms. In addition to policy and educational trends, this approach supported Bishop's work (2012) that children should be exposed to a variety of text, including familiar and unfamiliar worlds. With that guideline, it was important to next categorize the texts based upon genre and format. Relying again on the work completed by Crisp et al, (2016), categories included, (Galda et al 2014):

- Concept books

- Non-picture book

- Folklore

- Science fiction

- Fantasy

- Contemporary realistic fiction

- Historical fiction

- Nonfiction

- Poetry/rhyming

- Graphic novels

Per critical content analysis, assumptions and interpretations of the text will not be taken to maintain validity and rigor of the designated categories. As the RQ2 data asked the teachers to identify the selection of children's literature that they deem diverse in representation, it was critical for a different data analysis method to be utilized. As RQ2 sought to gain insight into how teachers represent diversity in children's literature, categorization of diversity representation 
was essential; therefore, the books were coded based upon diversity and children's literature genres. Following the lead of previous research, all books were independently coded first by the author and a second researcher, then together. The intercoder agreement checks and intercoder reliability process is described in the reliability section. After the data collection was completed, the researcher employed coding categories that had been successfully used with other data sets in previous critical content analyses and content analysis of depictions of multicultural or diverse cultural identities in children's literature (Crisp et al 2016; Crisp, 2015; Crisp \& Hiller, 2011; Sims, 1982). As shown in Table 2, diversity representation categories and meanings are presented.

\section{Table 2}

Diversity Representation Categories and Meanings

Code

Parallel cultures (primary)

Socioeconomic status and class

Dis/abilities, developmental differences, and chronic illness Sexual identity
Definition (Crisp et al, 2016)

Populations that exist in the United States and are often included in research and academia about diverse children's and young adult literature; populations may include African Americans, American Indians, Asian/pacific Americans, Latino/a Americans, middle eastern Americans, and mixedrace Americans

Depictions and/or themes that explicitly address depictions of ses and class

Depiction of people with dis/abilities, developmental differences, and chronic illnesses

Heterosexual categorization includes representations of characters with romantic and/or sexual attractions toward relationships with individuals described within the text towards members of the opposite sex

Lesbian category includes books where female characters were described as only having romantic and/or sexual attractions towards/relationships with individuals depicted as female

The code gay was used to include books where male characters were described as only having romantic and/or sexual attractions towards/relationships with individuals 
depicted as biological males

The code bisexual was used to categorize books depicting characters of any biological sex described as having romantic and/or sexual attractions toward/relationships with individuals of multiple biological sexes

Any depiction that did not fit within the stated categories were coded as other

Religion

Coded based on any specific religious tradition identified in the text; based upon the world's most prominent religions, categories included: Christian, Muslim, Hindu, Buddhist, Sikh, Jewish, Baha'i, nonreligious, agnostic, atheist, religious/nonspecific, and other

Gender

Gender identity; categorized based upon leading characters in books as cisfemale/ciswoman, cismale/cisman, transwoman, transman, ungendered, other, or n/a Language Categorized as books containing English only, other language (s) only, or multiple languages

Based upon the work completed by Crisp et al (2016), information on the dust jacket, Library of Congress information, leading characters/subjects, and the protagonists grounded the coding process. Information obtained from the dust jacket and Library of Congress are reflective of the text publication date. This approach permitted the researcher to view the content and categorize based upon representation over possible biased interpretations.

\section{Reliability}

To support the consistency of the study, reliability had been considered and was addressed with reasonable attention. As suggested by Miles et. al (2014), issues of quality and integrity, including intercoder agreement checks were established. The research questions were clear, the features of the study design were congruent with them, and there was consistency in the coding. For both RQ1 and RQ2 data analysis, a data collection protocol and coding scheme was clearly outlined, as noted in the titled section Analysis of RQ1 data and Analysis of RQ2 data. A second researcher was trained to use the research instruments. After the training, each 
researcher (the author and colleague) independently coded the data. Next, to establish coding consistency, after each coding cycle, the team met as a group. The approach to coding independently, then as a group provided the team with an opportunity to compare results and resolve any discrepancies in coding by reviewing differences for resolution. Once intercoder reliability was reached, summary sheets recorded the process, as well as provide documentation for accuracy. At least $80 \%$ inter-rater reliability was the goal for the analysis for RQ1 and RQ2 data sets; through discussion, $100 \%$ agreement was achieved.

\section{Validity}

To increase the validity of qualitative research, Mills and Gay (2019) suggests the employment of Guba's (1981) criteria for ensuring the validity of qualitative research. Guba (1981) argued that the trustworthiness of qualitative inquiry could be established by addressing the following attributes: credibility, transferability, dependability, and confirmability. Credibility is established through numerous means, including automated transcripts of the recorded interviews and peer debriefing through committee approval. Detailed demographics and contextrelevant statements was provided to increase transferability. Clearly defined research questions and the researcher's role and status has been provided as a dependability venue. The final validity characteristic that Guba (1981) suggests is confirmability. Much detail has been provided of the study's methods and procedures, as well as the data is available to access and retain. As presented in this chapter, this study aligns with the identified characteristics for validity of qualitative research.

\section{The Researcher}

The researcher has worked in an elementary school as an educator for seven years and in higher education as a full-time faculty member in a teacher education program for ten years. The 
researcher has completed various courses and has engaged in studies to obtain skills as a researcher. Finalized courses that have informed the researcher's qualitative research content knowledge include qualitative and quantitative studies. No participant will have a direct relationship with the researcher, such as a reporting or supervisor relationship, or any relationship with the researcher that would invoke bias on the research study. 


\section{Chapter IV: Findings}

\section{Introduction}

The purpose of this qualitative research study was to examine how in-service teachers perceive diversity, both in meaning and in depiction in children's literature. With the classroom population shifts and increased focused on diversity, it is critical to study how educators understand diversity, both in meaning and in children's literature. The study focused on the following research questions:

RQ1: How do educators define diversity?

RQ2: What children's literature do they consider is diverse in representation?

\section{Background Information}

The purpose of this chapter is to present the findings from descriptive case studies of two elementary educators and their understanding of diversity, both in meaning and in representation in children's literature. Description and discussion of the influential themes, including each participant's bioecologicalmodel is presented. Through the lens of a dual theoretical framework, Bishop's (1993) metaphorical notion of books as mirrors, windows, and sliding glass doors and Bronfenbrenner's bioecological model (1994), this study was situated in a position to examine the environmental framework of the teacher and children's literature as an influential entities in the classroom.

Two elementary educators were the focus of the case study. As the demographic profile presented characteristics of the participants, it is important to expand on the characteristics and provided a narrative to contextually situate and accompany the reader throughout the findings. As this study is situated in a dual theoretical framework, one that perceives children's literature as a means of reflection and our relationships are key 
developmental processes, it is necessary to view the teachers together. The dual narratives present their journeys as similar, yet different as both are educators with an ever-changing diverse classroom population. This theoretical approach highlights the importance of shared children's literature, prior experiences, relationships, and interactions, both directly and indirectly. As this research sought understanding of a teacher's perception and representation of diversity in a classroom setting, the bioecological model allowed the researcher to reveal multiple layers of an individual's influential factors and provided a holistic approach to their development. Bishop's (1993) metaphorical notion that children's literature serves as mirrors, windows, and sliding glass doors permitted the researcher to examine the identities represented in the children's literature and better understand the diverse categories reflected.

Throughout the data collection both teachers spoke more frequently about one identity category then others. Teacher 1 spoke frequently and referenced various cultures often. She shared a pivotal moment that she identified as influential in how she perceives diversity. Her interaction in a larger environment, the chronosystem, was self-identified as impactful in how she defines diversity. The reader will discover throughout the data set, that she aligned her understanding of diversity with the parallel cultures, (i.e., cultures often identified as underrepresented in children's literature).

While Teacher 1's conversation often included culture as an important aspect, in regards to perceptions of diversity, Teacher 2's dialogue varied somewhat. She mentioned different religions, when talking with her students and identified this characteristic in the children's literature she brought to the conversation on diversity. In her different systems, she often highlighted experiences with her students that directed 
her to selecting texts and designing instruction that addressed different religions. Both teachers approach diversity through different and personal perspectives. These perspectives are visually represented below in Figures 1 and 2. It is through these visuals that the reader is able to see how each teacher's perspectives are nested within the systems. Figure 1 presents a bioecological model visual of Teacher 1, while Figure 2 presents a bioecological model visual of Teacher 2 .

\section{Figure 1}

\section{Bioecological model visual of Teacher 1}

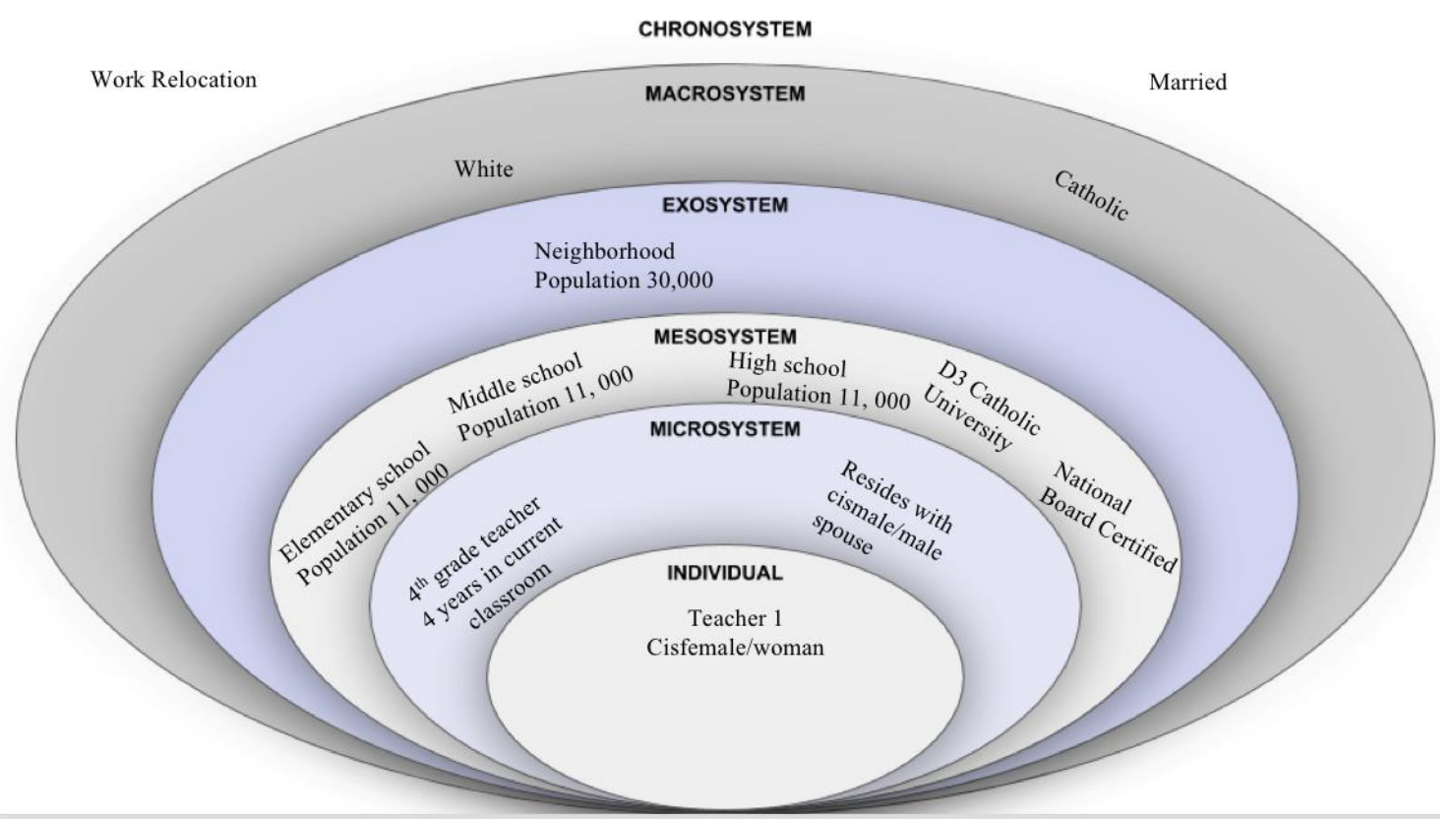


Figure 2

Bioecological model visual of Teacher 2

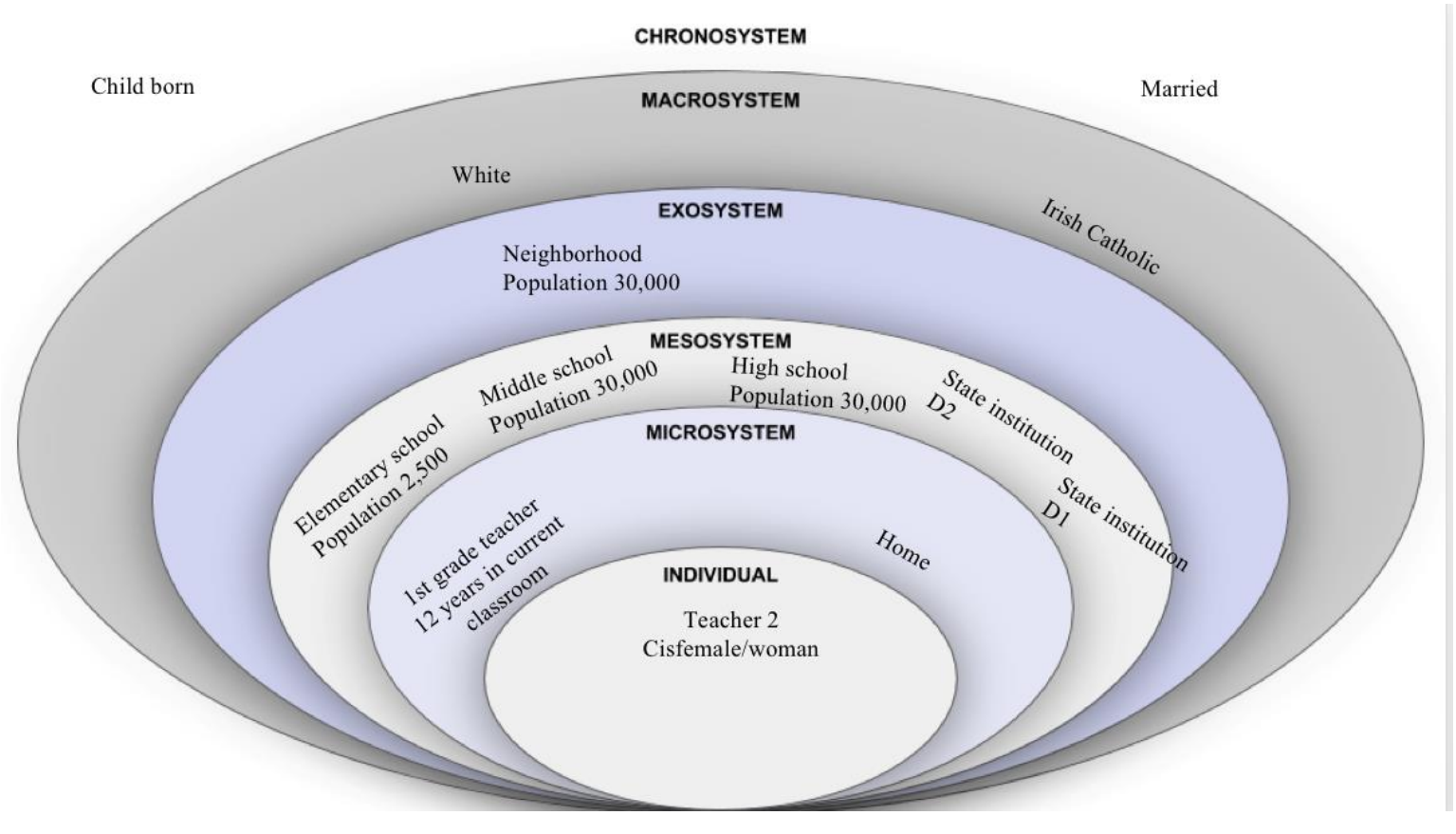

\section{Analysis of Research Question 1 \\ RQ1: How do educators define diversity? \\ Research Question 1 Findings}

To collect data for RQ1, a semi-structured interview and questionnaire was used with each participant. Prior to the interview, the questionnaire was completed independently. Next, the researcher conducted a semi-structured electronic interview. In the first cycle of coding, direct words and phrases were categorized in alignment with Table 3 ILA's 2017 Standards for Literacy Professionals Standard 4 Diversity and Equity Standards, PreK/Primary Classroom

Teacher Matrix (ILA, 2017). Intercoder reliability was met with 100\% agreement. As shown in

Figure 3, the results are provided of RQ1 first cycle coding and the distribution in alignment for Teacher 1 and Teacher 2. Then, the data was classified based upon Bronfenbrenner's bioecological model (1994). Only data that had been aligned to ILA's 2017 Standards for 
Literacy Professionals Standard 4 Diversity and Equity Standards, PreK/Primary Classroom

Teacher Matrix (ILA, 2017) was aligned to Bronfenbrenner's bioecological model (1994).

Figure 4 presents the second cycle coding approach and the classification of the data based upon Bronfenbrenner's bioecological model (1994) for Teacher 1 and for Teacher 2. To answer RQ1, it was imperative to align the participants' voice to educational policies and gain insight into their prior experiences, relationships, and interactions through identification of their bioecological model. The authentic voices and stories reflected in the interviews aligns with Bishop's (1990b) work that children's literature is an important socialization agent and provider of cultural systems and individualized values and behaviors.

Table 3

ILA's 2017 Standards for Literacy Professionals Standard 4 Diversity and Equity Standards, PreK/Primary Classroom Teacher Matrix (ILA, 2017)

\begin{tabular}{|c|c|c|c|c|}
\hline $\begin{array}{l}\text { Standard } 4 \\
\text { Diversity and } \\
\text { equity }\end{array}$ & Component 4.1 & Component 4.2 & Component 4.3 & Component 4.4 \\
\hline $\begin{array}{l}\text { Candidates } \\
\text { examine their } \\
\text { own culture and } \\
\text { beliefs; set high } \\
\text { expectations for } \\
\text { their students; } \\
\text { learn about and } \\
\text { appreciate the } \\
\text { cultures of their } \\
\text { students, } \\
\text { families, and } \\
\text { communities to } \\
\text { inform } \\
\text { instruction }\end{array}$ & $\begin{array}{l}\text { Candidates } \\
\text { recognize how } \\
\text { their own } \\
\text { cultural } \\
\text { experiences } \\
\text { affect instruction } \\
\text { and appreciate } \\
\text { the diversity of } \\
\text { their students, } \\
\text { families, and } \\
\text { communities }\end{array}$ & $\begin{array}{l}\text { Candidates set } \\
\text { high } \\
\text { expectations for } \\
\text { learners and } \\
\text { implement } \\
\text { instructional } \\
\text { practices that are } \\
\text { responsive to } \\
\text { students' } \\
\text { diversity }\end{array}$ & $\begin{array}{l}\text { Candidates } \\
\text { situate diversity } \\
\text { as a core asset in } \\
\text { instructional } \\
\text { planning, } \\
\text { teaching, and } \\
\text { selecting texts } \\
\text { and materials }\end{array}$ & $\begin{array}{l}\text { Candidates forge } \\
\text { family, } \\
\text { community, and } \\
\text { school } \\
\text { relationships to } \\
\text { enhance } \\
\text { students' literacy } \\
\text { learning }\end{array}$ \\
\hline
\end{tabular}




\section{Figure 3}

RQ1 Teacher 1 and Teacher 2 Results of First Cycle Coding Aligned to ILA Standard 4

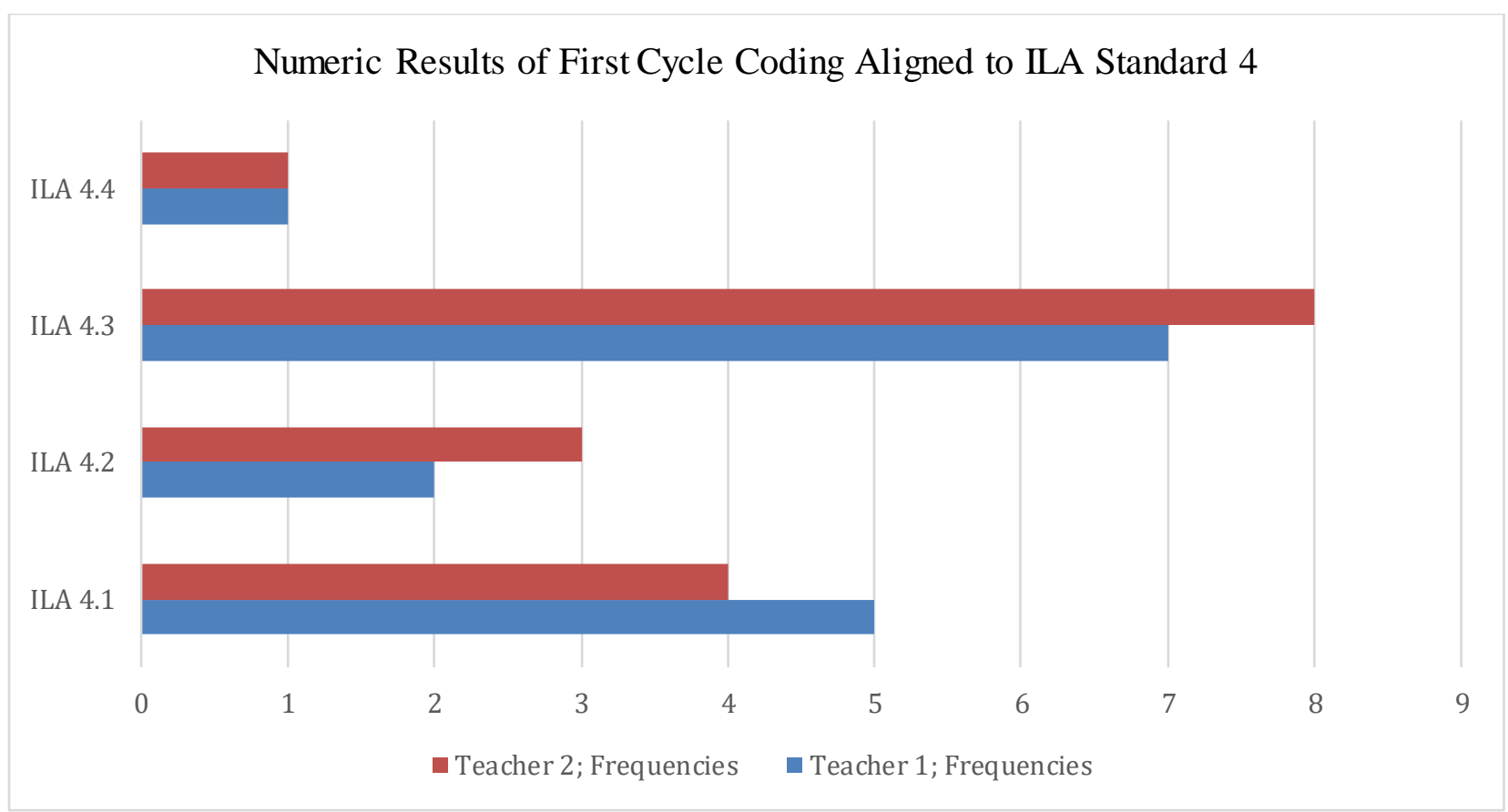

Figure 4

Second Cycle Coding Approach and the Classification of the Data Based upon Bronfenbrenner's Bioecological Model (1994) for Teacher 1and Teacher 2

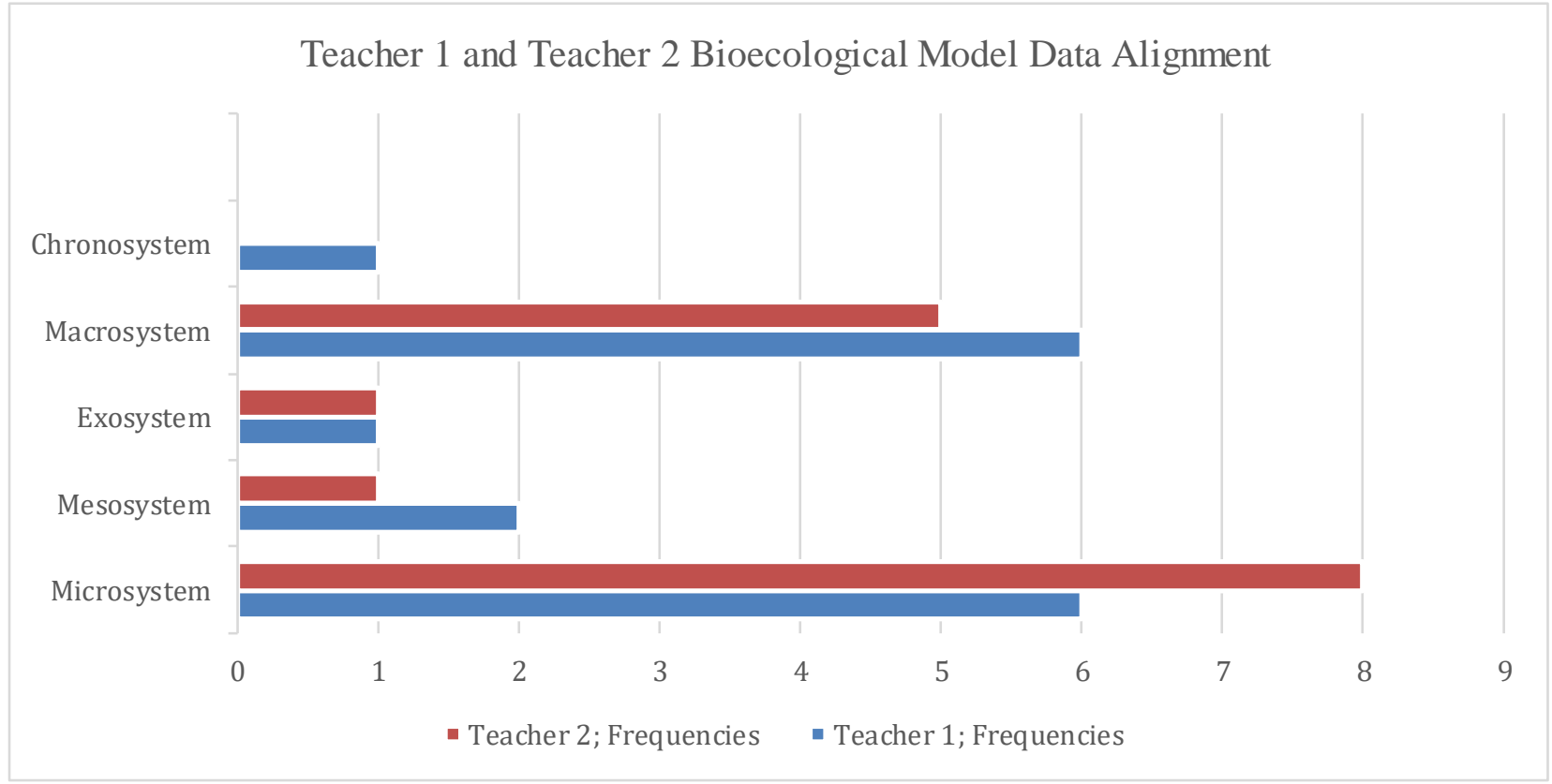


As the study sought to gain understanding of how teachers perceive diversity, the twostep cycle coding process permitted the researcher to categorize the data based upon literacy initiatives that places expectations on the teacher to demonstrate awareness and respect of diversity. In addition, the dual cycle coding process reflects the processes and interactions that were influential in the teachers' development of their perception of diversity. This route positioned the study to explore emerging themes and an understanding of how teachers define diversity.

In Bronfenbrenner's Bioecological Model (1994), the microsystem is the most proximal setting in which a person is situated. As it contains the individual's immediate environmental setting, Bronfenbrenner (1994) situates the microsystem as the most influential level of the systems theory. As a classroom teacher was the participant in this study, examples would include their home, place of work, his/her classroom, and the interactions between the teacher and his/her students. This system level acknowledges the influence of interactions that are face-toface and have interpersonal roles and relations that engage over time, (Bronfenbrenner, 1994). For Teacher 1, the microsystem, macrosystem and Standard 4.3 emerged as the most prominent in how she defined diversity. For Teacher 2, it was the microsystem and Standard 4.3 that had the most frequency counts.

Intimate personal experiences were identified as pivotal in the development of their definition, as well as key in situating diversity as a core asset in instructional planning, teaching, and selecting texts and materials (ILA, 2017). Both teachers frequently positioned their most proximal setting (i.e., their classroom and place of work) as an influential factor in design of instruction, planning, and choice of children's literature reflective of diversity. The following 
data exemplifies both teachers situating diversity as a core asset in instructional planning, teaching, and selecting texts and materials influenced by the microsystem. Teacher 1 placed the emphasis on an interaction in the work place as a driving force in situating diversity as a core asset in planning. For Teacher 1, the perception of diversity and instructional planning was impacted by prior relationships:

Teacher 1: "At a school that I worked at...there were comments made by the other teachers that were definitely discriminatory, and it made me feel really uncomfortable...I guess I had more of the attitude that racism isn't really a thing... and then I saw racism was actually happening in my work environment... and that really affected me so then I made it a point to counteract it in my own classroom..."

In regard to diversity, Teacher 1 referenced numerous texts that were deemed of importance to employ in the most proximal setting; the classroom. For Teacher 1, representations and perceptions of diversity includes ethnicity and sharing different perspectives:

Teacher 1: "There are a lot of books that I am fan of that I have not necessarily gotten to use yet in my classroom, like 'Inside Out and Back Again'...It's a novel set after the Vietnam War... about a family of refugees from Vietnam and it's told from that girl's point of view."

In situating diversity as a core asset, Teacher 2 identified interpersonal relationships and dialogue in the classroom as an influence in instructional planning and selecting texts as a response to placing diversity essential. For Teacher 2, ethnicity and skin color was included in perceptions of diversity:

Teacher 2: "Their little minds explode over Martin Luther King, Jr. Oh my goodness, they just don't get that all! Yeah, I try to expose them, but they just don't get it at all. What do you mean black people couldn't eat with white people and they couldn't go to school together? And I tell them, 'no, it was against the law and you could get into big trouble.' ...In first grade, they have no frame of reference...I'll say about five years ago, I stopped all together with 9/11... because these kids were not around for 9/11... And, all they hear is bad people with dark skin came and flew their planes into buildings and killed. That's when I was like, all right, maybe I quit reading that book (September 12: We Knew Everything Would be Okay)." 
Interpersonal dialogue and personal experiences within the classroom, (the microsystem), impacted Teacher 2's decision to place diversity as a core asset in instructional planning and selection of texts and materials. Diversity was defined here as differences in religion, ethnicity, and culture:

Teacher 2: "For one, all the characters in it are African American...we don't see that in a lot of our literature at all... Then, I had to bring up a map and show them where the country of Chad was...They are not used to anything that is not the United States....I couldn't imagine my teacher reading us a book about a school in Chad, but I think that was the norm in our area."

Teacher 2: "I remember when I did the history of St. Valentine's Day...They (first grade students) were like, 'What do mean a saint? How do you become a saint?' And, I'm like, I can't get into all this religious stuff, maybe I shouldn't have gone down this avenue...I didn't realize that they were going to ask me all of these questions."

For Teacher 1, the microsystem and macrosystem had the same number of occurrences coded as perceptions of diversity. For Teacher 2 , the macrosystem coded as second highest frequency count. The macrosystem is the cultural environment and embraces the institutional systems of a cultural or subculture. It is the overarching belief system that includes the society, the cultural values, and socioeconomic status of the person, (Bronfenbrenner, 1994). Examples of data that was included in this category included data that referenced populations that are typically included in research about diverse children's and young adult literature and religious traditions and beliefs. For Teacher 1, perceptions of diversity included ethnicity and parallel cultures:

Teacher 1: “(That is My Dream! A Picture Book of Langston Hughes' Dream Variation... I like to read it...It's a picture book about Langston Hughes... he's on a train and thinking back on his poetry and experiences."

Teacher 1: "This is not necessarily an example. It's kind of a book that promotes being welcoming to all cultures, 'I Promise' by Lebron James. I read it on the first day of school and it is about being a good citizen." 
Teacher 1: "Hidden Figures... It is about black women working at NASA...Things were very segregated and they were not being treated equal so I think (it is diverse) by showing a group of women who persevered, despite being discriminated against."

Reflective of the ideologies of a culture, Teacher 2 situated diversity as differences in religion, including the associated traditions and the belief systems of those religions:

Teacher 2: "I have several different holiday themed books, like Kwanza and Ramadan...My students have no idea what those holidays are even about...So I would say those are diverse based on religious background.

Teacher 2: "All they know is really Christianity, they don't know any other types of churches or you know people that don't celebrate Christmas, they don't understand that...It's really hard for them to grasp that concept. There's so little amounts of that here."

For both participants, the $1^{\text {st }}$ cycle of coding, alignment to literacy initiatives occurred in the same frequency and order. The $2^{\text {nd }}$ cycle of coding brought forth a slight difference in frequency of the identified system level deemed as influential in defining diversity. For Teacher 1 , the microsystem and macrosystem tied in frequency count. For Teacher 2 , the microsystem had eight frequency counts, then the macrosystem appeared in five occurrences when coded in how the participants define diversity. The frequency of interaction importance varied slightly after the microsystem and macrosystem.

For both participants, in how they defined diversity, interactions aligned in both the mesosystem and exosystem. The mesosystem is a combination of interactions between different parts of a person's microsystem, for example a child's mesosystem might be home and the school. Connected bioecological systems influenced both teachers' perceptions of how they discussed diversity. For Teacher 1, the library as a child was a place of interactions and experiences. Teacher 1 reflected on limited exposure to diverse books as influential in perspective, as compared to children's literature on present-day bookshelves: 
Teacher 1: "I was very much a reader and I went to the library a lot. I read whatever books were in the library. There definitely weren't as many books from diverse perspectives, like done today."

For Teacher 2, communities within the school shape the definition of diversity. While Teacher 2

is an active participant in her own classroom and school, additional classroom communities

within the school contribute still have an effect on development. Teacher 2 identified

developmental differences as a means of diversity:

Teacher 2: "We go over autism...there is a book in the caddy corner in my room about autism.... There is an autism room across from our classroom so they have some awareness that those kids have a special setup for them... We go over special needs with the special needs preschool being across from us...So diversity for the special education that we talk about."

As with the mesosystem, both participants had data align in the exosystem; however, not as prominent as the microsystem and macrosystem. The exosystem references to interactions and experiences where the individual is not an active participant; however, indirectly influences the individual. Examples of the exosystem include the work life of a partner or parent, mass media, and the individual's neighborhood. Teacher 1 cited the demographics of the community as a factor in being conscious of the shared texts in the classroom. For Teacher 1, different viewpoints and cultures were referenced as a means of diversity:

Teacher 1: "I really try to be conscientious of bringing in diverse text, because the area I am in teaching in is not a very diverse one, or at least my school isn 't' so I really try to expose the kids to different viewpoints and cultures. I try to seek out books like that."

For Teacher 2, defining diversity included socioeconomic status and race. While Teacher 2 is not an active participant in in the students' neighborhood; nevertheless experiences its influences and recognizes the impact on perceptions of diversity: 
Teacher 2: “I mean, it's so white here. There's very little skin color change, all the houses are kind of alike... in this area you don't have \$5 million dollar homes. You are either poor or middle class."

For the participants, it was only Teacher 1 with data coded at the chronosystem level. The chronosystem is the overarching system that includes major life transitions, such as marriage, moving, divorce, and historical events. Teacher 2 did not identify an event that was categorized at the chronosystem level. At the beginning of the chapter, it was presented that Teacher 1 spoke frequently as diversity encompassing different cultures, while Teacher 2 presented dialogue that centered more around religion. Teacher 1 identified a dynamic transition that affected the development of her perception of diversity. For Teacher 1, an educational experience that included living, working, and teaching in a different geographic location for a time period was impactful in how the participant defined diversity:

Teacher 1: "My first year of teaching, I did a program where they choose the location and school for you...I lived and taught in the south central region of the United States...My students were predominantly African American and Hispanic... Most of my students and families were Spanish speaking. When the parents would come to conferences, we would often have to translate with an older sibling...I think being there... and teaching in an environment like that, where I didn'tnecessarily look like my students or have the same experiences (impacted how I perceive diversity) ... I feel what really opened my eyes was when I started to realize these kids, when they saw commercials on TV or when they go to the movie theater or something like that, they are not seeing a lot of people look like them. Or, when you're at the store looking for toys...I would go get them little gifts and I'd be like 'Oh, it's all like white kids' and couldn't find anything. They were not being represented and I saw how important representationfor them...So, that was definitely eye-opening."

\section{Analysis of Research Question 2}

RQ2: What children's literature do they consider is diverse in representation? 


\section{Research Question 2 Findings}

One of the study's objectives was to identify children's literature that teachers view as diverse in representation. This was appropriate to complete as children have the right to see themselves, as well as unfamiliar worlds, in children's literature (Bishop, 2012). For an authentic response, and one reflective of the teachers' voice, it was essential to ask the participants this question in an interview setting. Both participants were asked to think about the books that they use in their classroom and which ones do they consider diverse in representation. While they were not specifically asked to identify a certain number of books, each participant provided 6 titles of children's literature that they deemed diverse in representation. After data collection was complete, the research team completed the content analysis based upon an instrument utilized in similar types of research (Crisp et al., 2016). This approach categorized the identified children's literature into various identity categories, genre, and format. This made sense as Bishop's (1993) mirrors, windows, and sliding glass doors metaphorical notion supports the exposure to an array of stories. To avoid assumptions, the research team exclusively used text information found in the Library of Congress. This information provided the research team with the data to code books for depictions of identity categories, genre, and format. Specifically, the coding of identity categories aligns with the pedagogical basis of Bishop's work (1990) and intentionally positioning underrepresented identities and experiences as central to students' lives in the classroom. Following the lead of similar types of research (e.g., Crisp et al., 2016) when determining representations of identity categories, genre, and format, books may be coded in more than one representation. The 
identification of the subject, person, or people on whom and what the book is focused grounded the research team in those representations.

The total texts coded as including explicit depictions of various identities was 12 . As stated, following the lead of previous similar research, it was agreed that books may be coded in more than one identity categories. Of the total 12 books identified, $58.3 \%$ of the books depicted at least one leading character or subject identified as belonging to a parallel culture, (populations that are often included in research about diverse children's and young adult literature, i.e. Asian/Pacific Americans, Middle Eastern Americans et al.). In the religion identity category, $33.3 \%$ of the books were fulfilled that criteria. In the gender identification category, $17 \%$ of the books were coded in the designated representation When coding books for depictions in the identification categories, the results revealed 3 of the identity categories were not represented: socioeconomic status and class, dis/abilities, developmental differences, and chronic illness, and sexual identity. Figure 5 presents the percentage of texts coded for explicit depictions of the various identity categories, (e.g., parallel cultures, gender).

\section{Figure 5}

Percentage of Total Texts Coded for Explicit Depictions of Identity Categories 
Pecentage of Texts Coded for Explicit Depictions of Identity Categories

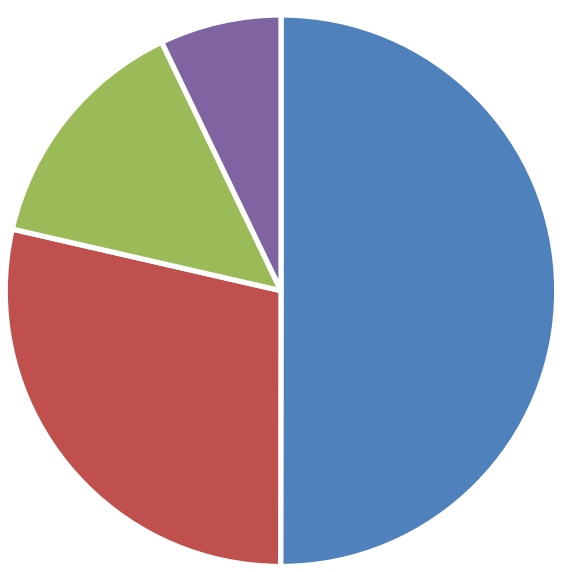

- Parallel Cultures

- Religion

- Gender

- Books that did not fit within any of the identity categories

As this study was situated in a binary theoretical framework that includes a bioecological model, it is important to also separately present coding results of each participant. Once more, the intentional sharing of data together and as an individual aligns with the dual theoretical framework, providing multiple stories and respecting one's unique experiences and interactions as part of the developmental process. For Teacher 1, 100\% were categorized in the parallel cultures identify category, while $33 \%$ were also categorized in the gender identity category. Content analysis for Teacher 1 revealed that socioeconomic status and class, dis/abilities, developmental differences, and chronic illness, sexual identity, and religion were not represented in the given text titles. Of the 6 books that Teacher 2 provided as diverse in representation, $66.6 \%$ were coded as books that contained depictions of religion, while $16.6 \%$ depicted at least one leading character or subject identified as belonging to a parallel culture and $16.6 \%$ was coded as a 
book that did not fit within any of the identity categories. For Teacher 2 , representation of diverse identities did not include socioeconomic status and class, dis/abilities, developmental differences, and chronic illness, sexual identity, and gender. To visually present and compare the identity categories represented, a percentage narrative was essential. Percentages exceed $100 \%$ due to the ability of the texts to fulfill multiple categories. To look at the data of each participant, Figure 6 independently presents the percentage of texts coded as including explicit depictions of various identity categories that Teacher 1 and Teacher 2 designated as diverse in representation.

\section{Figure 6}

Teacher 1 and Teacher 2 Percentage of Texts Coded as Including Explicit Depictions of Various Identity Categories

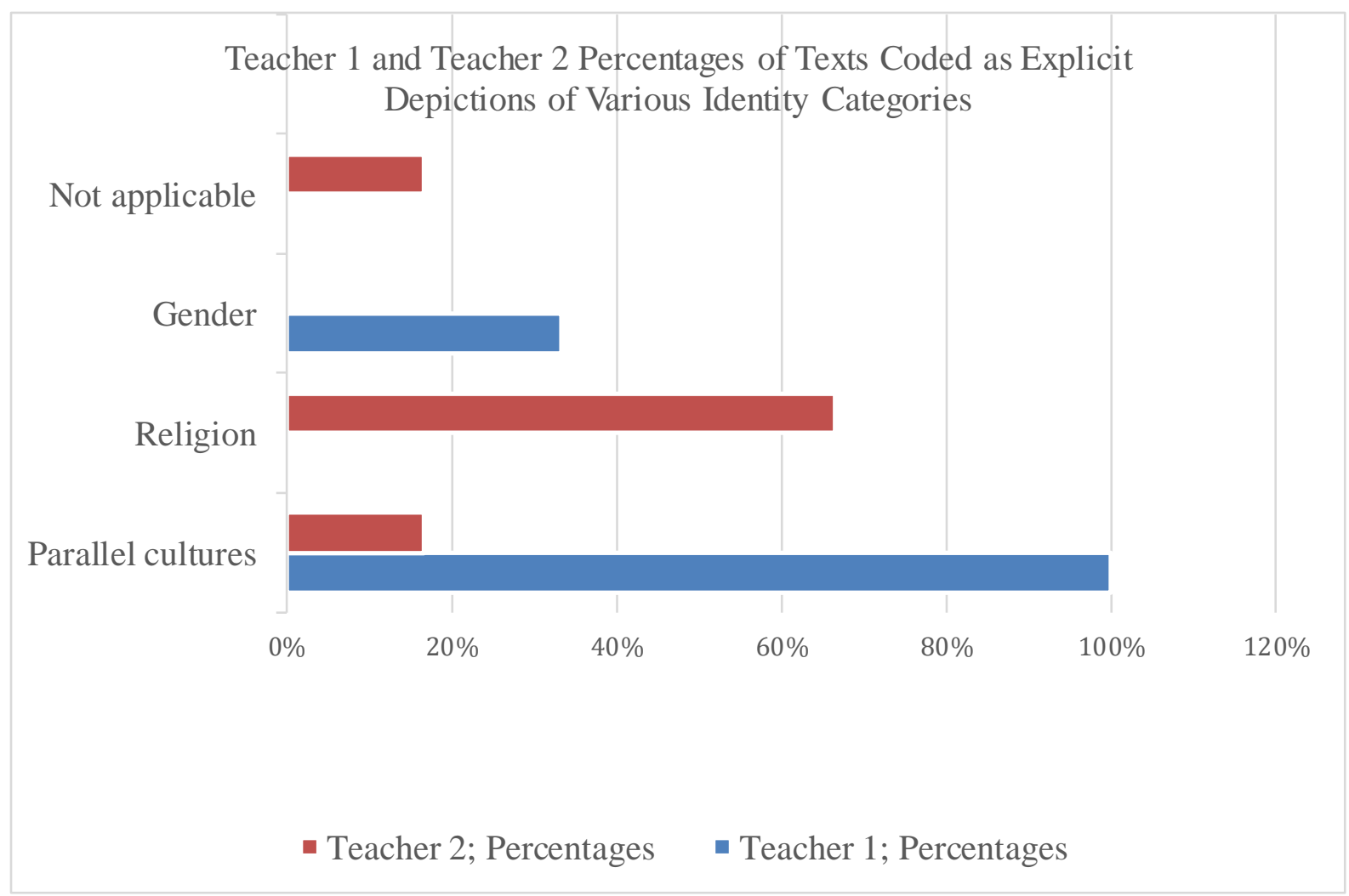


While the content analysis coded books as explicit depictions of various identity categories, the texts were also categorized on genre and text format. This was important as current educational and legislation policies encourage a balance of genres and formats to be utilized in the classroom. Each book was coded on basic categorizations of genre and text format (Galda et al., 2014). As with the identity categories, it was agreed that books could be coded in more than one genre and/or format. For example, a book could be coded as a concept book (text that support student understanding of ideas, patterns, relationships, etc..) and a nonpicture book (e.g., anthologies, novels). Poetry/rhyming and non-picturebook each represented $25 \%$ of the total texts coded for genre/format. Historical fiction and contemporary realistic fiction each fulfilled $8.3 \%$ of the total texts coded for genre and format. The diversity of texts according to the categories of genre and format did not include folklore, fantasy, graphic novels, and science fiction. Figure 7 presents the percentage of total texts coded to the genre (s) and format (s) it represented.

\section{Figure 7}

Percentage of Total Texts Coded for Genre(s) and Format (s) 


\section{Percentage of Total Texts Coded for Genre(s) and Format(s)}

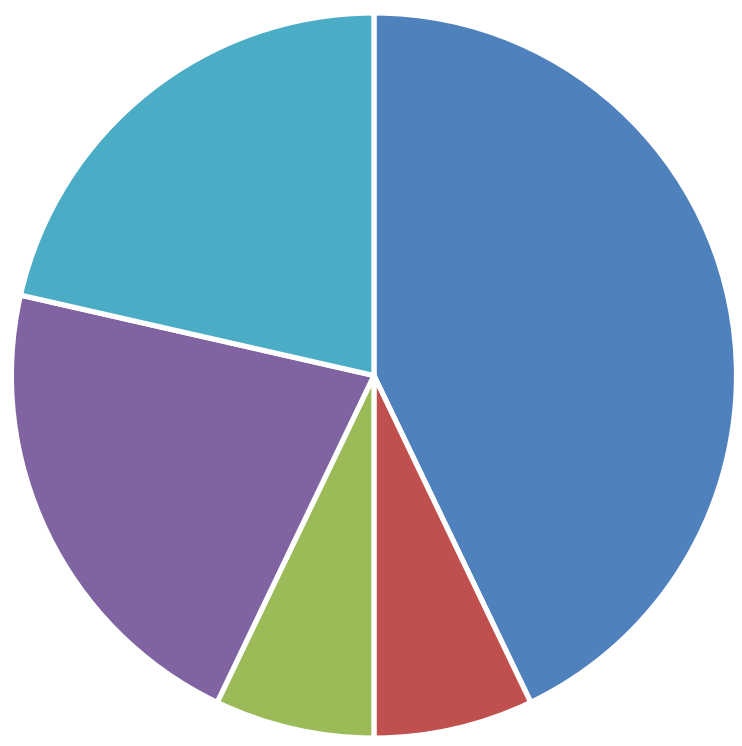

- Concept Books

- Historical Fiction

- Poetry/Rhyming
- Contemporary Realstic Fiction

- Nonfiction

Because of the dual theoretical framework that included a bioecological model of each participant and children's literature as a means of identity reflection, once more it was important to also independently present the genre and format coding results. Of the texts that Teacher 1 identified as diverse in representation, $50 \%$ of the books fulfilled the poetry/rhyming genre and format. Concept books and non-fiction each represented $33.3 \%$ of the texts coded for genre and format, while $16.6 \%$ of the texts were classified historical fiction. For Teacher 1, fantasy, graphic novels, science fiction, and contemporary realistic fiction categories were not represented in the genre and format coding cycle. For Teacher 2, the presented books deemed as diverse in representation, $66.6 \%$ were coded as concept books, $16.6 \%$ as non-picturebook, and $16.6 \%$ as contemporary realistic fiction. None of the following genres and formats were coded as folklore, poetry/rhyming, fantasy, historical fiction, graphic novels, and science fiction. It was important 
to present the texts coded in percentage narrative to visually demonstrate range of genres and formats, including a visual comparative of Teacher 1 and Teacher 2. Percentages exceed 100\% due to the ability of texts to fulfill multiple categories. Figure 8 presents the visual independent representation of Teacher 1 and Teacher 2 basic categorization of book genres and text formats.

\section{Figure 8}

Teacher 1 and Teacher 2 Percentage of Texts Coded for Genre and Format

Teacher 1 and Teacher 2 Percentages of Texts Coded for Genre and Format

Contemporary Realstic Fiction

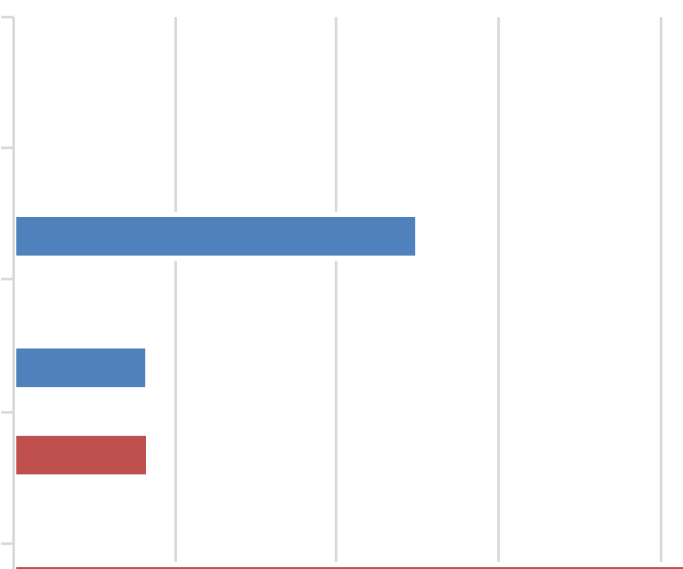

Non-picturebooks

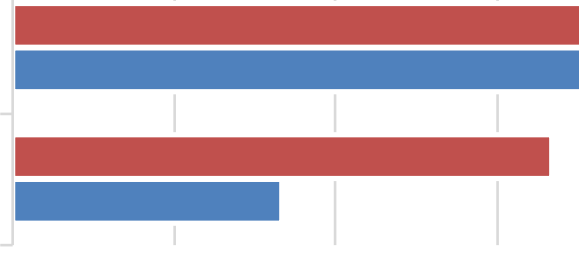

$0 \%$

$20 \%$

$40 \%$

$60 \%$

$80 \%$

$100 \%$

$120 \%$

- Teacher 2; Percentages - Teacher 1; Percentages

\section{Conclusion of the Findings}

To understand how the participants defined diversity, it was essential to explore not only how they perceive diversity, but also how they represent diversity with children's literature. In seeking to understand how teachers define diversity, it was critical to go beyond just asking them to define the term. A systemic view of development provided an opportunity to consider the 
bioecological processes, including relationships and interactions within one's environment, that are influential in conceptualizing diversity. The findings present an analogous relationship between one's perceptions and representations of diversity aligned to developmental processes that one experiences over time. This made sense because Bishop's (2012) work emphasizes the importance of children's literature as a socializing agent.

At the end of the interview, both participants were asked to define diversity. For Teacher 1, diversity including perspectives:

"I think about it as being inclusive of people of all races and cultures and nationalities and kind of shifting away from a predominantly white Caucasian perspective to include more voices and perspectives. "

This definition is reflected in Teacher 1's ecological journey, instructional practices, and children's literature that employed in the classroom to situate diversity as a core assets. Prior personal experiences, including community demographics and interactions in a work setting, were pivotal in how Teacher 1 views diversity. The microsystem, the most proximal setting in which a person is situate, and the macrosystem, the overarching belief system, were the most prominent in Teacher 1's definition of diversity. It was important for Teacher 1 to expose students to multiple voices and that was reflected in Teacher 1's children literature that was considered diverse in representation. The majority of Teacher 1's book titles were coded as explicitly depicted people identified as members of parallel cultures and the books were used exemplify the metaphorical notion of books as mirrors, windows, and sliding glass doors.

For Teacher 2, again, the representation and perception of diversity was aligned to Teacher 2's external influences and interactions over time. Teacher 2's direct definition of diversity was:

"It is what makes you unique, whether it is your religious background or skin color or physical ability, your mental ability, or your culture." 
The microsystem and macrosystem proved to be influential in instructional planning and selecting texts when situating diversity as a core asset in the classroom. The intimate dialogue that occurred between Teacher 2 and the students impacted instructional decisions, often focusing on different religions. Holidays and discussion of traditions were frequent conversations in Teacher 2's classroom. It was important for Teacher 2 to utilize texts and highlight various religions and cultural traditions, including Kwanzaa, Ramadan, and Valentine's Day. This aspect of defining diversity is reflected in Teacher 2's developmental environment:

"In my childhood, we had a lot of Italian traditions, like the Feast of the Seven Fishes that you do at Christmas...A lot of Americans do the turkey and mashed potatoes and sweet potatoes and your teachers were always asking about which one of those were your favorite, and all of the holiday glyphs, and I'm like there's no baked ziti!'”

With the majority of Teacher 2's children literature identified as diverse in representation coded as featuring religion, this key transaction process is reflected in Teacher 2's bioecological model. 


\section{Chapter V: Conclusion and Discussion}

\section{Introduction}

The purpose of this chapter is to present a discussion and conclusion of the study. The chapter first presents the key take-aways and implications from the study. The chapter then concludes with recommendations for future research, practice, and discussion.

\section{Conclusions}

Situated in a binary theoretical framework, the study sought to explore how teachers define diversity and perceive representation of diversity in children's literature. A descriptive case study was enacted as the most appropriate means to achieve this goal. The data analysis brought forth several implications important to highlight.

First, representation of diversity through children's literature correlates with one's bioecological model. When the findings are viewed through the binary theoretical framework, the data revealed that there is a correlation of one's evolving bioecological model to the children's literature that one identifies as diverse. The children's literature that Teacher 1 classified as diverse in representation was reflected in her bioecological model, and the same occurred with Teacher 2. Reflective of her dialogue, identity categories that were represented were mostly religion in Teacher 2's designated diverse children's literature. For both teachers, the identified children's literature text that represented diversity reflected interactions, relationships, and experiences with various aspects within their environment and their bioecological model.

Second, each teacher's perception of diversity aligned with her own bioecological model, including personal experiences and interactions. The proximal processes and the development processes of interaction between person and environment emerged in their perception of 
diversity (Bronfenbrenner \& Evans, 2000). Teacher 1 defined diversity as all races, cultures, and nationalities and the importance of the inclusion of more voices and perspectives; this was reflected numerous times in her interview. While Teacher 1's definition represented a more inclusive view of diversity and embraced all cultures and multiple perspectives, Teacher 2's definition varied slightly. Once more, the definition of diversity aligned with the individual's interactions and experiences. This aligns with Bronfenbrenner's view of development as emerging from the interaction of individual and context, (Bronfenbrenner, 1994). While Teacher 2's definition of diversity included a broader array of differences, her dialogue theme included more conversions centered mostly around religion, with some reference to parallel cultures. As similar to Teacher 1, Teacher 2's interactions with her environment and proximal processes were in her perceptual development of diversity. Teacher 1 and Teacher 2 presented two unique perceptions of diversity; however, it was their narrative that provided a glimpse of the participation one plays in his or her own development, including defining diversity.

Third, although educational trends and legislation policies suggest a wide array of genres and format, this was not mirrored in the overall selection of identified children's literature. For Teacher 1, poetry, concept books, contemporary realistic fiction, and nonfiction were included in the genres and formats of the identified children's literature. Fantasy, folklore, graphic novels, historical fiction, and science fiction were not represented in Teacher 1's genre and format coding cycle. For Teacher 2, the presented books deemed diverse in representation, included mostly concept books, with one non-fiction and one contemporary realistic fiction. Genres and formats not included were non-picturebooks, folklore, science fiction, fantasy, historical fiction, poetry/rhyming, and graphic novels. 
Fourth, through children's literature, not all identity categories are being represented in the classroom. Of the children's literature identified diverse in representation, the results revealed 3 of the identity categories were not represented at all: socioeconomic status and class, dis/abilities, developmental differences, and chronic illness, and sexual identity. This finding counters some similar work that has previously been completed in this area. While their work was limited to preschool libraries and did not explore the classroom teacher's utilization of diverse children's literature, Crisp et. al (2016) found that the greatest representation of early childhood bookshelves were gender identity and the least represented included religion.

Finally, behind each classroom, there is a teacher with a story to tell. It is their narrative that can be reflective of both their understanding and implementation of educational policies and legislation trends. Gaining insight into each teacher's perception of diversity required the researcher to examine multiple layers that influenced the teacher's definition of diversity. The interview and questionnaire were aligned with questions and prompts that reflected the bioecological model of human development. While both teachers are elementary educators with similar journeys, their stories are unique. To understand a teacher's pedagogical design, it is important to ask them "why" and "how', to allow their authentic voice to be shared. Bishop (1993) situates children's literature as an opportunity to send diverse and equitable messages to children. The messages that Teacher 1 and Teacher 2 are sending, via children's literature, are indicative of their individualized perspective of diversity. The continuity and change that has occurred in both of their lives, over time, has impacted their perspective of diversity. Their perspective of diversity is mirrored in their representation of children's literature that they deem as diverse in representation. 


\section{Recommendations of Future Research}

The purpose of the study was to explore how teachers define diversity and what children's literature do they identify as diverse in representation. The findings presented that an educator's interactions and experiences play a role in shaping perceptions and representations of diversity. The research was situated in dual theoretical framework that viewed one's development as evolving, including their perceptions and representations. Based upon the finding, recommendations of future research include teacher discourse around diverse children's literature, exploration of the utilization of diverse children's literature in teacher educati on programs., and a content analysis of children's literature that is included in the grade-level curriculum.

For both in-service and pre-service teachers, it would be advantageous to complete an analysis on teacher discourse centered around diverse children's literature. What does the dialogue around children's literature deemed diverse in representation sound like? Are educators engaging in conversation where they may feel uncomfortable and uncertain of how to answer student-driven questions? In addition, this exploration presents the possibilities of bringing awareness to conversations around children's literature that educators may or may not be participating in, which could be the focus of future professional learning opportunities.

Future research should also include an exploration of the utilization of diverse children's literature in teacher education programs. As research in the field suggestions, preservice teachers need courses that involve diverse pieces of children's literature so that they can develop a social critical consciousness, in order to support the children's literature selections, they use with their students (McNair, 2003; Sharp, Medrano, \& Coneway, 2018). Therefore, an in-depth 
examination of how diverse children's literature is presented and utilized in teacher education programs would present the ability to impact future preparation program development.

A final recommendation for future research should include a content analysis of children's literature that is include in the grade-level curriculum. How is diversity represented in district-adopted reading curricula and program stories? When asked to identify children's literature that was diverse in representation, only Teacher 2 referenced one text from her reading manual. "Honestly there is not that much diversityin our book...there is one that is about this little school in Chad... all of characters in it are African-American...we don't see a lot of that in our literature at all" (Personal Interview, 2021).

As legislation policies and education trends are placed on elementary educators to offer a range of genres and formats in an inclusive classroom, a content analysis, with a lens on identity categories, of the required reading program is creditable. A comprehensive curriculum study may reveal identity categories that are underrepresented in the text that is being shared; therefore, impact and awareness of curricula is a viable possibly worthy of pursuit.

\section{Recommendations of Future Practice}

As the findings revealed a correlation between a teacher's perceptions and representations of/in? diversity, this study presents recommendations of future classroom practice. In terms of the study, the teachers revealed interactions, contextual conditions, and processes that were reflected in the children's literature identified as diverse in representation. The study's binary theoretical framework provides a foundational platform and scaffold for educators seeking to gain a better understanding of their perceptions and representations of diversity. Recommendations include educators constructing a bioecological model for reflective practice, the utilization of Bishop's mirrors, windows, and sliding glass doors as a pedagogical 
basis in selecting children's literature that is diverse in representation and an increased awareness of exposing students to more than one story.

Bronfenbrenner's bioecological theory is a useful model for understanding the bidirectional interactions between various systems that influence one's evolving development. An advantageous movement for teachers seeking awareness of one's understanding of diversity would be to examine and complete an analysis of their own bioecological model of human development (Bronfenbrenner, 1993). It would be beneficial for teachers to have a greater knowledge of the proximal processes, (the driving forces of human development), and the role of person characteristics in development (Bronfenbrenner \& Evans, 2000). The influential nature of one's bioecological model has the opportunity to promote a greater understanding and awareness of one's development, specifically, perceptions of diversity. A construction and reflection of an educator's bioecological model presents the opportunity for transformation, an opportunity to examine the relationships and settings, that over time, have influenced development.

While it is suggested for educators to construct their own bioecological model to encourage reflection, the study also recommends educators to consider the application of Bishop's metaphor “windows, mirrors, and sliding glass doors, (1993). The metaphorical notion of the transformational nature of children's literature provides a pedagogical perspective useful for educators. Both professional development and classroom applications, Bishop's work presents educators with an opportunity to review the children's literature that they utilize in the classroom. The review of one's children literature that is being presented as diverse in representation may help to promote a rich and varied selection of books that represent multiple identity categories. 
Building upon and connecting the finds to the theoretical dual framework, the importance of exposure to a rich and varied children's literature is solidified with Chimamanda Ngozi Adichie's 2009's TED Talk lecture on dispelling stereotypes through children's literature and the dangers of the single story. Adichie's concept of the single story builds upon Bishop's (1993) windows, mirrors, and sliding glass doors metaphorical notion and connects Bronfenbrenner's bioecological model (1996) by the pivotal role and experience that children's literature accomplishes in the classroom. It establishes children's literature as a tool to promote moving beyond one story projected in the classroom. "The single story creates stereotypes, and the problem with stereotypes is not that they are untrue, but that they are incomplete. They make one story become the only story" (Adichie, 2009, para. 24). This perspective builds upon the notion that books serve as mirrors, windows, and sliding glass doors and the role that children's literature fulfills in the classroom. Children's literature has a profound impact on children in the classroom and the way they view themselves and the world. It is essential to understand that there is never a single story about a place, person, or group of people; rejection of the single story encourages one to understand empathy and common humanity.

It is imperative to understand that action is critical for change. Merriam-Webster define social construct as an idea that has been created and accepted by the people in a society. Boyd et. al (2015) expressed their meaning of diversity, as a social construct, as complex, complicated, multidimensional, and fluid. Freire,(1970), argued that people must develop critical conscientious and engage educational practices that integrate theory, action, and reflection as a venue towards social change and justice. For diverse representation in literature to occur, educators must be deliberate and reflective in their actions.

\section{Discussion}


Through the binary combination of theoretical lenses, the study presented the importance of the analogous relationship between two elementary educators' life experiences, their perceptions and how the perceived diversity to be represented in the children's literature they chose to use with their students. As presented, the classroom demographics are ever-changing, as is an educator's evolving development. The study revealed that one's bioecological model reflects influential moments and experiences that correlate to one's perception and representation of diversity. As one's development is as evolving as the classroom landscape, the nuances of diversity are dynamic. The elementary educator and the children's literature that is employed to support diversity in the classroom presents a transformational opportunity for social justice and change. As Adichie, (2009) proclaims:

Many stories matter. Stories have been used to dispossess and to malign. But stories can also be used to empower, and to humanize. Stories can break the dignity of a people. But stories can also repair that broken dignity... When we reject the single story, when we realize that there is never a single story about any place, we regain a kind of paradise. (Speech transcript]

More than one story matters. The field of education needs to pursue this so that all students are supported through children's literature in the classroom. Perspectives and reflections must be shared to best understand educators' design, delivery, and representation of diversity. As it is critical to recognize each student as an individual, it is equally important to hear the educator's story. Educators' prior experiences, relationships, and interactions influence pedagogical practices and selection of children's literature utilized in the classroom. Every educator has a journey; it is critical for the field of education to appreciate those voices to recognize how educational policies and trends are implemented. The diverse population of our classroom 
includes both students and educators. Narratives are powerful, narratives are authentic, narratives are transformational. 


\section{References}

Adams, W. (2015). Conducting semi-structured interviews. In K.H. Newcomer, Handbook of Practical Program Evaluation (pp.492-504). San Francisco: Jossey-Bass.

Adichie, C. (n.d.). The danger of a single story. Retrieved July 7, 2020, from Ted Talks: http://www.ted.com/talks/chimiamanda_adichie_the_danger_of_a_single_story.html

Association, I. L. (2018). Standards for the preparation of literacy professionals 2017. Newark, DE.

Association, I. L. (2020, January 18). Classroom Matrix by Role. Retrieved January 2020, from Internationl Literacy Association: www.literacyworldwide.org

Bandura, A. (1977). Social learning theory. Englewood Cliffs, NJ: Prentice Hall.

Baratz, L. (2015). Children's books about special needs used a mediating tool, the perceptions of inclusion classroom teachers in mainstream schools. Higher Education Studies, 5(1), 5162.

Beauchat K., B. K. (2009). Building preschool childrens' language and literacy one stor ybook at a time. The Reading Teacher, 26-39.

Beck, L. (2010). Half-full or half-empty. Journal of Literacy Research, 42(1), 94-99.

behind, N. c. (2002). No child left behind: A desktop reference. Washington, D.C. : U.S. Department of Education, Elementary and Secondary Education.

Bengtsson, M. (2016). How to plan and perform a qualitative study using content analysis. NursingPlusOpen, 8-14.

Bishop, R. (1990a, Summer). Mirrors, windows, and sliding glass doors. Perspectives: Choosing and using books for the classroom, 6(3), pp. 9-12. 
Bishop, R. (1992). Extending multicultural understanding. In B. Cullinan, Invitation to read: More children's literature in the reading program (pp. 80-91). Newark, D.E. : International Reading Association.

Bishop, R. (2012). Reflections on the development of African American children's literature. Journal of Children's Literature, 38(2), 5-13.

Bishop, R. S. (1990b). Walk tall in the world: African American literature for today's children. The Journal of Negro Education, 59(4), 556-565.

Boyd, F. C. (2015, February). Cuturally diverse literature: Enriching variety in an era of common core state standards. The Reading Teacher, 68(5), pp. 378-387.

Bridges, L. (1995). Creating your classroom community. York, M.E. : Stenhouse.

Brinson, S. (2012). Knowledge of multicultural literature among early childhood educators. Multicultural Education, 19(2), 30-33.

Bronfenbrenner, U. \&. (2000). Developmental science in the 21st century: Emerging theoretical models, research designs, and empirical findings. Social Development, 115-125.

Bronfenbrenner, U. \&. (n.d.). The bioecological model of human development. In D. W. Lerner, Handbook of Child Development: Vol. 1. Theoretical Models of Human Development (pp. 793-828). Hoboken, NJ: Wiley.

Bronfenbrenner, U. (1979). The Ecology of Human Development: Experiments by Nature and Design. Cambridge, MA: Harvard University Press.

Bronfenbrenner, U. (1994). Ecological models of human development. International encyclopedia of education, 1643-1647. 
Bureau, U. C. (2018). Census Reporter Profile page for McMechen, WV. Retrieved from American community survey 5-year estimates: http://censusreporter.org/profiles/16000US5450260

Butler, B. (1982). Reading begins at home. Theory into Practice(21), 308-314.

Classroom diversity. (2012). Retrieved from The IRIS Center: https://iris.peabody.vanderbilt.edu/module/div/

Cook, K. E.-V. (2006). Bibliotherapy. Intervention in School and Clinic, 42(2), 91-100.

Crisp, T. K. (2016). What's on our bookshelves? The diversity of children's literature in early childhood classroom libraries. Journal of Children's Literature, 29-42.

Davis, L. (2015). Diversity. In R. R. Adams, Keywords for disability studies. Credo Reference: https://wvu.idm.oclc.org/login?url=https://search.credoreference.com/content/entry/nyupr esskds/diversity/0?institutionId=735: New York University Press.

Dictionary, A. R. (2019). Diversity. Retrieved from Credo Reference: https://wvu.idm.oclc.org/login?url=https://search.credoreference.com/content/entry/allsab /diversity/0?institutionId=735

Dictionary, C. (2020, July 16). Cambridge Dictionary. Retrieved July 16, 2020, from Cambridge Dictionary: https://dictionary.cambridge.org/us/dictionary/english/diversity

Diehl, S. \&. (2010). Clinical discourse and engagement during shared storybook reading in preschool groups. Seminars in Speech and Language, 111-121.

Duggins, S. \&. (2017). Reading aloud in an era of common core: An exploratory study of the perspectives of primary teachers serving African American children in low income communities. Journal of Early Childhood Literacy, 1-27. 
Duggins, S. \&. (2017, July). Reading aloud in an era of common core: An exploratory study of the perspectives of primary teachers serving African American children in low-income communities. Journal of Early Childhood Literacy, 1-27.

Education, U. S. (1983). A nation at risk: The imperative for educational reform. Washington, D.C.: The National Commission on Excellence in Educatipn.

Education, U. S. (2002). No child left behind: A desktop reference. Washington, D.C.: Education Publications Center.

Fleer, M. \&. (2005). Literacy and numeracy: A review of the literature. Washington, D.C. : Department of Education, Employment and Workplace Relations.

Galda, L. C. (2009). Literature and the Child. (7th, Ed.) Beverly, MA: Wadsworth Publishing.

Gamse, B. B. (n.d.). Reading first impact study: Interim report (NCEE 2008-2016). National Center for Educationl Evaluation and Regional Assistance, Institute of Education Sciences. Washington, D.C.: U.S. Department of Education.

Guba, E. (n.d.). Criteria for assessing the trustworthiness of naturalistic inquiries. Educational Communication and Technology, 75-91.

Hancock, M. (2000). A celebration of literature and response. Boston: Pearson.

Herlihy, C., Kemple, J., Bloom, H., Zhu, P., \& Berlin, G. (2009). Understanding reading first: What we know, what we don't, and what's next. New York: MDRC .

Holland, K. \&. (2016). Elementary teachers' perspective on the use of multicultural literature in their classrooms. Language and Literacy, 16-32.

Horning, K. L. (2015). CCBC Choices 2015. Madison: Cooperative Children's Book Center, University of Wisconsin-Madison. 
Horning, K. L. (2016). CCBC choices 2016:Cooperative children's book center. Madison: Uniersity of Wisconsin-Madison.

Hsiu-Fang, H. \&. (2005). Three approaches to qualitative content analysis. Qualitative Health Research, 1277-88.

International Literacy Association Standards. (2020, October 27). Retrieved from International Literacy Association : https://literacyworldwide.org/get-resources/standards/standards2017?Site=ILA

Keller, T. (2020). When you trap a tiger. New York: Random House Children's Books.

Kelly, L. \&. (2018). Children's literature that sparks inferential discussions. The Reading Teacher, 21-29.

Kelly, L. O. (2019). Collaborative conversations: Speaking and listening in the primary grades. Young Children, 30-36.

Kemmerlin, C. \&. (2020). Promoting elementary students' awareness of diversity and social justice through interactive read-alouds. The International Journal of Learner Diversity and Identities, 34-48.

Koralek, D. (2001). Reading aloud with children of all ages. In J. Trelease, The Read Aloud Handbook (5th ed., pp. 1-6). New York: Penguin Putman.

Koss, M. J. (2018). Mapping the diversity in caldecott books from 1938 - 2017: The changing topography. Journal of Children's Literature, 4-20.

Lavrakas, P. (2008). Encyclopedia of survey research methods. Sage.

Lea, B. (2015). Children's books about special needs used as a mediating tool, the perceptions of inclusion classroom teachers in mainstream schools. Higher Education Studies, 5(1), 5162. 
Leahy, M. F. (2018). Diversity in children's literature. World Journal of Educational Research, $5(2), 172-183$.

Lefebvre, P. T. (2011). Enhancing vocabulary, print awareness and phonological awareness through share storybook reading with low income preschoolers. Journal of Early Childhood Literacy, 11(4), 453-479.

Leu, D. J. (2003). Toward a theory of new literacies emerging from the internet and other information and communication technologies $=$. In R. R. Unrau, Theoretical models and processes of reading. Newark, DE: International Reading Association.

Lyon, G. S. (2005). Evidence-based reading policy in the United States: How scientific research informs instructional practices. Brookings Papers on Education Policy, 209-248.

McNair, J. (2003). But the five Chinese brothers is one of my favorite books! Conducting sociopolitical critiques of children's literature with preservice teachers. Journal of Children's Literature, 46-54.

Merriam-Webster. (2020, July 16). Merriam-Webster. Retrieved July 16, 2020, from MerriamWebster: https://www.merriam-webster.com/dictionary/diversity

Mihic, S. M. (2017). The role of bibliotherapy and therapeutic storytelling in creating inclusive classroom communities. In C. P. Curran, Handbook of Research on Classroom Diversity and Inclusive Education Practice (pp. 375-399). Hershey, PA: IGI Global.

Miles, M. H. (2014). Qualitative data analysis. Thousand Oaks, CA: Sage Publications, Inc. . Mills, G. \&. (2019). Educational research: Competencies for analysis and applications. New York, NY: Pearson.

Mills, G. \&. (2019). Educational research: Competencies for anaylsis and applications. New York, NY: Pearson. 
Mol, S. \&. (2011). To read or not to read: A meta-analysis of print exposure from infancy to early adulthood. Psychological Bullentin.

Morawski, C. (1997, January/February). A role for bibliotherapy in teacher education. Reading Horizons: A Journal of Literacy and Language Arts, 37(3), 243-259.

Morawski, C. G. (2000). Interactive bibliotherapy as an innovative inservice practice: A focus on the inclusive setting. Reading Horizons, 41, 48-64.

National Center for Education Statistics. (2021, June 27). Retrieved from Institute of Education Science: https://nces.ed.gov/ccd/districtsearch/district_detail.asp?ID2=5400750

National Governors Associatio Center for Best Practices, C. o. (2010). Common core state standards. Washington, D.C.: http://corestandards.org/.

Officers, N. G. (2010). Common Core State Standards for English language arts and literacy in history/social studies, science, and technical subjects. . Washington, D.C.

Panel, N. E. (2008). Developing early literacy: Report of the national early literacy panel. Washington, D.C. : National Institute for Literacy.

Patt, M. \&. (1993). Gender equity in picture books in preschool classrooms: An exploratory study. Eric Digest.

Pearson, P. (2010). Reading first: Hard to live with-or without. Journal of Literacy Research, 42(1), 100-108.

Portnoy, D. P. (2015, 6). Immigrant struggles, immigrant gifts. . Educational Leadership, 72(9), $22-27$.

Rosa, E. \&. (2013). Urie Bronfenbrenner's theory of human development: Its evolution from ecology to bioecology. Journal of Family Theory and Review 5, 243-258. 
Rosenblatt, L. (1978). The reader, the text, the poem: The transactional theory of the literary work. Carbondale, IL: Southern Illinois University Press.

Rosenblatt, L. (1986). The aesthetic transaction. Journal of Aesthetic Education(20), 122-127.

Saldana, J. (2009). The coding manual for qualitative researchers. Sage Publishers Ltd.

Saldana, J. (2012). The coding manual for qualitative researchers. Thousands Oaks, CA: Sage.

Saldana, J. (2013). The coding manual for qualitative researchers. London: Sage.

Serafina, F. \&. (2014). The roles of children's literature in the primary grades. The Reading Teacher, 465-468.

Sharp, L. M. (2018). What's the story with children's literature? A content analysis of children's literature courses for preservice elementary teachers. Reading Horizons.

Statistics, N. C. (2019). The condition of education 2019. U.S. Department of Education. U.S. Department of Education.

Straner, N. (2011). Moving "eco" back into socioecological models: A proposal to reorient ecological literacy into human developmental models and school systems. Human Ecology Review, 167-173.

Tarbutton, T. (2018). Leveraging 21st century learning and technology to create caring diverse classroom cultures. Multicultural Education, 4-6.

Thompson, A. \&. (n.d.). Introduction: Diversity. In Encyclopedia of diversity and social justice. Credo Reference: https://wvu.idm.oclc.org/login?url=https://search.credoreference.com/content/entry/rowm andasj/introduction_diversity/0?institutionId=735: Rowman \& Littlefield Publishers.

Tracey, D. \&. (2006). Lenses on Reading. New York: The Guilford Express. 
Tunks, K. G. (2015). A survey of teachers' selection and use of children's literature in the elementary classroom. The Language and Literacy Spectrum, 25.

Vygotsky, L. (1993). The collected works of L.S. Vygotsky (Vol. 2). New York, NY: Plenum Press.

Wei, L. M. (2018). How can teachers faciliate productive small-group talk? The Elementary School Journal, 579-609.

(2020). What's hot in literacy report. Newark, D.E. : International Literacy Association.

Yokota, J. (2001). Kaleidscope: A multicultural booklist for grades K-8. Urbana, IL: National Council of Teachers of English. 


\section{Appendix A Definition of Terms}

1. Diversity: Goes beyond race and ethnicity; the definition encompasses physical and mental disabilities, socioeconomic status, language variations, dialect differences, religion, family structure, as well as sexual and gender identity (Boyd et al., 2015).

2. Multicultural: Can be narrowly defined to imply ethnicity and race, (Holland \& Mongillo, 2016). A broader term, multicultural may encompass racial and ethnic backgrounds, in addition to a variety of cultural groups. Diversity, conversely, is complex, multidimensional, and fluid (Koss, Johnson, \& Martinex, 2018). 


\section{Appendix B Interview Instrument}

1. Think about your children's literature library and selection that you currently use in your classroom. List 5 titles, (include the title and author), that you identify as diverse in representation and explain why.
1.
2.
3.
4.
5.

2. How do you use those books? When and why do you use these books?

3. Have you ever experienced any barriers when using any of these books in the classroom?

4. Describe the type of children's literature that you were exposed to as child. As a young adult?

5. Describe the type of children's literature that was shared with you in your teacher education program of study.

6. When you completed your teacher education program of study, how was children's literature introduced and/or integrated?

7. Describe your home growing up as child. With whom, did you have the most contact and interactions with?

8. In your childhood home, were there cultural values and traditions that was reflected in your home setting?

9. As a child, describe your closest peer and the interactions you had with them.

10. Growing up, how would you describe your socioeconomic status?

11. If your primary childhood caregivers worked outside of the home, where did they work? Were you able to go to work with them on occasions?

12. Describe your interactions with the mass media.

13. In your lifetime, have there been any life experiences, whether directly or indirectly, that you feel have impacted your perspective on diversity?

14. How do you define diversity?

15. Based upon that definition, what do you feel influenced your definition of diversity? 


\section{Appendix C Questionnaire}

The purpose of this study is to investigate how Elementary teachers define diversity and represent diversity in children. All identities will be kept confidential and pseudonyms will be used. Thank you for your time answering this questionnaire.

1. What is your gender do you identify with?

Female Male Other

2. What is your ethnicity? Please highlight/circle
a. Caucasian
b. African American
c. Pacific Islander
d. Asian
e. Native American
f. Hispanic
g. Other (please specify):

3. What is your highest completed education level?
a. Bachelor's
b. Master's
c. Doctorate
e. Other

4. Indicate the year (s), name (s), and location (s) of each institution that you attended:

5. How many years have you been teaching:

a. At your current school:

b. Other locations, (please describe the geographic location of other work institutions based upon the descriptors in question 7)

6. As an elementary student, what city/town and state was your school located?

7. As a middle school student, what city/town and state was your school located?

8. As a high school student, what city/town and state was your school located?

9. The current location of your school, (where you are currently employed as an elementary classroom teacher), what city/town and state is it located? 


\section{Appendix D Dual Theoretical Framework Alignment to Instrument Design Crosswalk}

\begin{tabular}{|c|c|c|}
\hline & $\begin{array}{l}\text { Bishop's (1993) } \\
\text { metaphorical } \\
\text { notion of books as } \\
\text { mirrors, windows, } \\
\text { and sliding glass } \\
\text { doors }\end{array}$ & $\begin{array}{l}\text { Bronfenbrenner's } \\
\text { (1994) } \\
\text { bioecological } \\
\text { model }\end{array}$ \\
\hline What is your gender do you identify with? & & Microsystem \\
\hline What is your ethnicity? & & Macrosystem \\
\hline What is your highest completed education level? & & Microsystem \& \\
\hline $\begin{array}{l}\text { Indicate the year (s), name (s), and location (s) of each } \\
\text { institution that you attended }\end{array}$ & & $\begin{array}{l}\text { Microsystem \& } \\
\text { Mesosystem }\end{array}$ \\
\hline $\begin{array}{l}\text { When you completed your undergraduate teacher } \\
\text { education program, did the institution qualify as a: }\end{array}$ & & $\begin{array}{l}\text { Microsystem \& } \\
\text { Mesosystem }\end{array}$ \\
\hline $\begin{array}{l}\text { How many years have you been teaching: } \\
\text { At your current school: } \\
\text { Other locations }\end{array}$ & & $\begin{array}{l}\text { Microsystem \& } \\
\text { Mesosystem }\end{array}$ \\
\hline $\begin{array}{l}\text { The geographic location of your undergraduate teacher } \\
\text { education program }\end{array}$ & & Macrosystem \\
\hline The geographic location of your elementary school & & Macrosystem \\
\hline The geographic location of your middle school & & Macrosystem \\
\hline $\begin{array}{l}\text { As a high school student, how would you describe the } \\
\text { geographic location of your high school }\end{array}$ & & Macrosystem \\
\hline $\begin{array}{l}\text { The current location of your school, (where you are } \\
\text { currently employed as an elementary classroom teacher) }\end{array}$ & & Macrosystem \\
\hline $\begin{array}{l}\text { Describe your home growing up as child. With whom, did } \\
\text { you have the most contact and interactions with? }\end{array}$ & & $\begin{array}{l}\text { Microsystem \& } \\
\text { Mesosystem }\end{array}$ \\
\hline $\begin{array}{l}\text { As a child, describe your closest peer(s) and interactions } \\
\text { with them. }\end{array}$ & & $\begin{array}{l}\text { Microsystem \& } \\
\text { Mesosystem }\end{array}$ \\
\hline $\begin{array}{l}\text { Growing up, how would you describe your socioeconomic } \\
\text { status }\end{array}$ & & Macrosystem \\
\hline $\begin{array}{l}\text { If your primary childhood caregivers worked outside of } \\
\text { the home, where did they work? Were you able to go to } \\
\text { work with them on occasions }\end{array}$ & & Exosystem \\
\hline Describe your interactions with the mass media & & Exosystem \\
\hline $\begin{array}{l}\text { In your life time, have there been any normative and } \\
\text { nonnormative life transitions that you have experienced? } \\
\text { For example, sociohistorical events, marriage, divorce, } \\
\text { winning the lottery }\end{array}$ & & Chronosystem \\
\hline How do you define diversity? & $\mathrm{X}$ & \\
\hline
\end{tabular}


MORE THAN ONE STORY: A BIOECOLOGICAL MODEL

\begin{tabular}{|l|c|c|}
\hline & & $\mathrm{X}$ \\
\hline $\begin{array}{l}\text { Based upon that definition, what do you feel influenced } \\
\text { your definition of diversity? }\end{array}$ & $\mathrm{X}$ & $\mathrm{X}$ \\
\hline $\begin{array}{l}\text { Describe the type of children's literature that you were } \\
\text { exposed to as child. As a young adult? }\end{array}$ & $\mathrm{X}$ & $\begin{array}{l}\text { Microsystem, } \\
\text { Mesosystem, } \\
\text { Exosystem, } \\
\text { Macrosystem }\end{array}$ \\
\hline $\begin{array}{l}\text { Describe the type of children's literature that was shared } \\
\text { with you in your teacher education program of study. }\end{array}$ & $\begin{array}{l}\text { Microsystem, } \\
\text { Mesosystem, } \\
\text { Exosystem, } \\
\text { Macrosystem }\end{array}$ \\
\hline $\begin{array}{l}\text { When you completed your teacher education program of } \\
\text { study, how was children's literature introduced and/or } \\
\text { integrated? }\end{array}$ & $\mathrm{X}$ & $\mathrm{X}$ \\
\hline $\begin{array}{l}\text { Think about your children's literature library and } \\
\text { selection that you currently use in your classroom. List } 5 \\
\text { titles, (include the title and author), that you identify as } \\
\text { diverse in representation and explain why }\end{array}$ & $\mathrm{X}$ & \\
\hline
\end{tabular}




\section{Appendix E The ILA Standards for the Preparation of Literacy Professionals 2017 Standard 4 Diversity and Equity}

Adapted from Standards for the Preparation of Literacy Professionals 2017

(C) 2018 by the International Literacy Association

Pre-k/primary classroom teacher

Classroom Matrix by Role

\begin{tabular}{|l|l|l|l|l|}
\hline Standard & Component 1 & Component 2 & Component 3 & Component 4 \\
\hline $\begin{array}{l}\text { Standard 4: } \\
\text { diversity and } \\
\text { equity candidates } \\
\text { examine their } \\
\text { own culture and } \\
\text { beliefs; set high } \\
\text { expectations for } \\
\text { their students; } \\
\text { learn about and } \\
\text { appreciate the } \\
\text { cultures of their } \\
\text { students, } \\
\text { families, and } \\
\text { communities to } \\
\text { inform } \\
\text { instruction. }\end{array}$ & $\begin{array}{l}\text { instruction and } \\
\text { appreciate the } \\
\text { diversity of their } \\
\text { students, } \\
\text { families, and } \\
\text { communities. }\end{array}$ & $\begin{array}{l}\text { 4.2 candidates } \\
\text { set high } \\
\text { expectations for } \\
\text { learners and } \\
\text { implement } \\
\text { instructional } \\
\text { practices that are } \\
\text { responsive to } \\
\text { students' } \\
\text { diversity }\end{array}$ & $\begin{array}{l}\text { 4.3 candidates } \\
\text { situate diversity } \\
\text { as a core asset in } \\
\text { instructional } \\
\text { planning, } \\
\text { teaching, and } \\
\text { selecting texts } \\
\text { and materials }\end{array}$ & $\begin{array}{l}\text { 4.4 candidates } \\
\text { forge family, } \\
\text { community, and } \\
\text { school } \\
\text { relationships to } \\
\text { enhance } \\
\text { students literacy } \\
\text { learning }\end{array}$ \\
\end{tabular}




\section{Appendix F Bronfenbrenner's Bioecological Model Theory Five Connected Configuration}

Microsystem: The most proximal setting in which a person is situated; Examples include the home, child care, playground, place of work et al...The setting allowed for interactions that are face-to-face and have interpersonal roles and relations that are engage in over time

Mesosystem: A system of microsystems; Active participation in a new setting and diminishes when the individual leaves; Examples include the interactions between a child's parents and teachers

Exosystem: The developing individual is not an active participant nor situated; never less, experiences its influences; Examples include mass media, the individual's neighborhood

Macrosystem: Embraces the institutional systems of a culture or subculture; an overarching belief system; Examples include ethnicity, geographic location and ideologies of the culture

Chronosystem: The overarching system; Normative and nonnormative life transitions, including sociohistorical events; Examples include marriage, divorce, winning the lottery. 